\title{
Amylose-Free ("waxy") Wheat Colonization by Fusarium spp. and Response to Fusarium Head Blight
}

\author{
Deanna L. Funnell-Harris, ${ }^{1,2, \dagger}$ Robert A. Graybosch, ${ }^{1,3}$ Patrick M. O’Neill, ${ }^{1,2}$ Zachary T. Duray, $^{1,2}$ and Stephen N. Wegulo ${ }^{2}$ \\ ${ }^{1}$ Wheat, Sorghum and Forage Research Unit, United States Department of Agriculture-Agricultural Research Service, Lincoln, \\ NE 68583; ${ }^{2}$ Department of Plant Pathology, University of Nebraska, Lincoln, NE 68583; and ${ }^{3}$ Department of Agronomy and \\ Horticulture, University of Nebraska, Lincoln, NE 68583
}

\begin{abstract}
Hexaploid waxy wheat (Triticum aestivum L.) has null mutations in $W x$ genes and grain lacking amylose with increased digestibility and usability for specialty foods. The waxy cultivar Mattern is susceptible to Fusarium head blight (FHB) caused by Fusarium graminearum species complex, which produces the mycotoxin deoxynivalenol (DON). In experiment 1 , conducted during low natural FHB, grain from waxy breeding lines, Mattern, and wild-type breeding lines and cultivars were assessed for Fusarium infection and DON concentration. Nine Fusarium species and species complexes were detected from internally infected (disinfested) grain; F. graminearum infections were not different between waxy and wild-type. Surface- and internally infected grain

(nondisinfested) had greater numbers of Fusarium isolates across waxy versus wild-type, but $F$. graminearum-like infections were similar; however, DON levels were higher in waxy. In experiment 2, conducted during a timely epidemic, disease severity, Fusarium-damaged kernels (FDK), and DON were assessed for waxy breeding lines, Mattern, and wild-type cultivars. Disease severity and FDK were not significantly different from wild-type, but DON was higher in waxy than wild-type lines. Across both experiments, waxy breeding lines, Plant Introductions 677876 and 677877 , responded similarly to FHB as moderately resistant wild-type cultivar Overland, showing promise for breeding advanced waxy cultivars with reduced FHB susceptibility.
\end{abstract}

The waxy mutation, identified in wheat (Triticum spp.), other small grains, and other crops, reduces amylose content of the starch (Graybosch 1998). In wild-type (Waxy) plants, starch is made up of amylose and amylopectin: amylose makes up approximately onefourth of starch, and amylopectin constitutes the remaining portion (Fasahat et al. 2014; Maningat and Seib 2010). In general, the percentage of amylose in the starch is negatively correlated with digestibility (Svihus et al. 2005). Waxy (Wx) encodes for granule bound starch synthase (GBSS), which is critical for amylose production. Spontaneous or induced null mutations $(w x)$ in this gene can

${ }^{\dagger}$ Corresponding author: D. L. Funnell-Harris;

Deanna.Funnell-Harris@ars.usda.gov

Funding: This research was supported by U.S. Department of Agriculture Agricultural Research Service Current Research Information System project numbers 3042-21000-031-00D and 5440-21220-032-00D.

Mention of trade names or commercial products in this article is solely for the purpose of providing specific information and does not imply recommendation or endorsement by the U.S. Department of Agriculture (USDA). The USDA prohibits discrimination in all its programs and activities on the basis of race, color, national origin, age, disability, and where applicable, sex, marital status, familial status, parental status, religion, sexual orientation, genetic information, political beliefs, reprisal, or because all or part of an individual's income is derived from any public assistance program. (Not all prohibited bases apply to all programs.) Persons with disabilities who require alternative means for communication of program information (Braille, large print, audiotape, etc.) should contact USDA's TARGET Center at (202) 720-2600 (voice and TDD). To file a complaint of discrimination, write to USDA, Director, Office of Civil Rights, 1400 Independence Avenue, S.W., Washington, D.C. 20250-9410, or call (800) 795-3272 (voice) or (202) 720-6382 (TDD). USDA is an equal opportunity provider and employer.

*The $\boldsymbol{e}$-Xtra logo stands for "electronic extra" and indicates that two supplementary tables are published online.

Accepted for publication 16 November 2018.

This article is in the public domain and not copyrightable. It may be freely reprinted with customary crediting of the source. The American Phytopathological Society, 2019. significantly reduce amylose to nearly $0 \%$ of the starch (Lin et al. 2017; Morante et al. 2016; Nakamura et al. 1995; Sattler et al. 2009).

In hexaploid wheat, there are three structural genes, one on each of the three genomes (A, B, and D) encoding isoforms of GBSS that control amylose content in the endosperm of the grain (Miura et al. 1994). These enzymes are called GBSSI, to distinguish them from GBSSII, which is encoded by a separate set of genes (GBSSII) that control amylose content in other wheat tissues (Vrinten and Nakamura 2000). The presence of one or two waxy null alleles (i.e., single or double mutant in one or two genomes, respectively) results in production of reduced-amylose starch in the endosperm, called "partial waxy" (Graybosch 1998; Nakamura et al. 1993). Wheats with three null alleles (waxy mutations in all three genomes) produce essentially amylose-free starch (Graybosch 1998; Nakamura et al. 1995). Partial waxy wheats are sources of flour with optimal quality characteristics for specialty food products, particularly Asian noodles (Guo et al. 2003; Hung et al. 2006; Ramachandran et al. 2016). Amylose-free waxy wheats are valuable for production of modified food starches (Graybosch 1998), blending to formulate superior flours to be used for food products, or increased performance of baked goods and Asian salted noodles (Graybosch and Hansen 2016; Hung et al. 2006). Flours made from waxy wheat may also be used to extend the shelf life of baked goods (Bhattacharya et al. 2002; Graybosch 1998). Although the waxy trait was first reported in maize over 100 years ago (BeMiller 2009), waxy wheat development began just over 25 years ago (Nakamura et al. 1993; Seib 2000); currently, there are only three publicly available waxy wheat cultivars for use in major wheat-growing areas in the United States (Graybosch et al. 2014, in press; Morris and King 2007). The current study describes a set of waxy breeding lines adapted to the harsher conditions in the Northern Great Plains and their responses to natural infections by Fusarium spp. (Graybosch et al. 2018).

The reduction or lack of amylose in starch granules impacts the constituents of the grain. Total starch and protein concentrations were shown to be similar when comparing wild-type and waxy grain, but lipid and $\beta$-glucan concentrations were significantly greater in waxy wheat grain compared with wild-type or partial waxy (Ahuja et al. 2013). Starch of waxy grain was shown to have significantly different physicochemical properties than wild-type (Shevkani et al. 2017). These differences included higher thermal transition 
temperatures (onset and peak) for waxy starch, higher energy (enthalpy) required for gelatinization, and nearly half the time required to reach peak viscosity compared with wild-type; however, pasting temperatures (the temperature at which starch swelling begins) were similar (Demeke et al. 1999; Graybosch et al. 2000, 2003; Hung et al. 2008; Mangalika et al. 2003). The crystallinity of starch, as determined by X-ray diffraction analysis, was shown to be negatively associated with amylose content (Demeke et al. 1999; Fujita et al. 1998). Additionally, starch from waxy grains was shown to have significantly greater in vitro enzymatic hydrolysis compared with wildtype starch (Ahuja et al. 2013; Mangalika et al. 2003).

In the 2011 USDA-ARS coordinated Northern Regional Performance Nursery (NRPN), the waxy cultivar Mattern (tested experimentally as NX04Y2107), with three null alleles, was among the most susceptible to naturally incited Fusarium head blight (FHB). Observations of production fields near Mead, NE, also showed Mattern to be highly susceptible to FHB. A previous report of waxy sorghum indicated that it was not more susceptible to Fusarium grain pathogens compared with wild-type, whereas a report of reduced-amylose maize indicated increased susceptibility to Fusarium spp. (Funnell-Harris et al. 2015; Loesch et al. 1976). Therefore, it is unclear whether the physicochemical alterations in waxy starches affect interactions with pathogens in wheat, resulting in grain more susceptible to $F$. graminearum or other Fusarium pathogens. Under natural infection, Fusarium species can colonize the flowers or developing grain (Atanasoff 1920). Some may produce mycotoxins such as trichothecenes, enniatins, or moniliformin (Covarelli et al. 2015; Hietaniemi et al. 2016). These infections reduce grain quality and result in mycotoxin accumulation during grain development and in storage (Mylona et al. 2012; Osborne and Stein 2007). Grain fungal communities may be competitive or may coexist, thus potentially producing multiple mycotoxins (Czaban et al. 2015; Hietaniemi et al. 2016; Lutz et al. 2003; Nicolaisen et al. 2014; Wagacha et al. 2010).

One particularly insidious wheat grain disease is FHB, caused by several Fusarium species (Goswami and Kistler 2005; Spanic et al. 2010; Umpiérrez-Failache et al. 2013). Disease symptoms are visible within 3 to 4 days following infection and are manifested as premature whitening or bleaching of one or more spikelets on a head, which can progress to partial or entire whitening of the head. Diseased spikelets are sterile or contain shriveled kernels that appear chalky white or pink, referred to as Fusarium-damaged kernels (FDK), scabby kernels, or "tombstones" (McMullen et al. 2012). Fusarium graminearum Schwabe 1839 is the most commonly found species causing FHB in North America (Gilbert et al. 2014; Panthi et al. 2014; Vujanovic et al. 2012) and is capable of producing the trichothecene mycotoxin deoxynivalenol (DON) (Goswami and Kistler 2005). Although major occurrences can be sporadic, epidemics have increased since the early 1990s (Del Ponte et al. 2009; Duveiller et al. 2007; Zeller et al. 2003). The pathogen survives in crop debris on which the primary infectious propagules, ascospores, are generated (Gilbert and Fernando 2004; Manstretta et al. 2015). It has been shown that increased surface debris, particularly from wheat or maize crops as a result of reduced-tillage practices, can increase the incidence and severity of FHB (Bateman et al. 2007; Schaafsma et al. 2005). Moderate to warm temperatures and moisture in the form of rain or irrigation before and during anthesis favor FHB and mycotoxin production (Cowger et al. 2009; Osborne and Stein 2007). The disease results in deteriorated and shriveled grains, or asymptomatic grains, with high DON levels, that are essentially unusable for milling and down-stream uses (Cowger and Arrellano 2010; Tkachuk et al. 1991). These grain lots are often discounted or even rejected entirely at elevators, leading to substantial losses in revenue (Dahl and Wilson 2018; McMullen et al. 1997). DON is toxic to humans and animals at moderate to low exposure levels and has effects on gastrointestinal, reproductive, and immune systems (Katika et al. 2012; Raiola et al. 2015). Because DON is not heat labile, the toxin can be found in flour and baked goods (Savi et al. 2016; Trigo-Stockli et al. 1996; Zhang and Wang 2015).

A collection of waxy winter wheat breeding lines, most of which have recently been added to the USDA-ARS National Small Grains
Collection (Aberdeen, ID) as Plant Introductions (PI) (Graybosch et al. 2018), were developed to be adapted to the relatively harsh conditions in the Northern U.S. Great Plains (Paulsen and Shroyer 2008). These lines, the waxy wheat cultivar Mattern and wild-type breeding lines and cultivars, also adapted to this region, were grown for harvest in 2013, 2014, and 2015 in Nebraska. The waxy breeding lines and Mattern have the waxy allele in all three genomes. Trace to low FHB disease levels were observed in Nebraska during 2013 and 2014 (Baenziger et al. 2014, 2015), but during 2015 there was a severe FHB epidemic (Lilleboe 2015). Because decreased amylose content in wheat grain may affect interactions with $F$. graminearum and other Fusarium spp., these waxy breeding lines were assessed for infection by Fusarium species (2013 and 2014 grain) and FHB symptoms (2015) and mycotoxin accumulation (2013, 2014, and 2015). These studies were undertaken to determine whether Fusarium spp. infection rates and DON levels are similar in waxy versus wild-type grain under both low and high disease severities and whether genetic variation exists among waxy wheat lines in response to Fusarium pathogens.

\section{Materials and Methods}

Field plantings. Field studies were seeded as the wheat component of an oats (Avena sativa L.)/wheat/soy (Glycine max L.) rotation. The 13 waxy breeding lines (12 PIs and one unreleased line), the waxy cultivar Mattern (waxy check), and 18 Nebraska-adapted wild-type cultivars and breeding lines (wild-type checks) were grown during 2013 and 2014 at the University of Nebraska, Eastern Nebraska Research and Extension Center (ENREC) near Mead, NE. The waxy breeding lines and Mattern have three waxy alleles, and their pedigrees are presented in Table 1. Among the wild-type cultivars and breeding lines (Table 2), Overland has been reported to be moderately resistant to FHB (Jin et al. 2013), Wesley is considered moderately susceptible to FHB (Jin et al. 2013), and Jagalene is susceptible to FHB (Wegulo et al. 2011). In 2015, the breeding lines, Mattern, and a subset of three wild-type checks were grown at ENREC and at University of Nebraska, Havelock Farm, in Lincoln, NE, herein referred to as Havelock. The wild-type checks grown in 2015, Mace, Settler CL, and Overland, were chosen based on superior performance in Nebraska (https://cropwatch.unl.edu/wheat), or, in the case of Mace, for resistance to wheat streak mosaic virus. Each year at Mead, $89.6 \mathrm{~kg} / \mathrm{ha}$ of nitrogen (N) was applied at the fall planting along with Finesse herbicide (chlorsulfuron and metsulfuron methyl), and in the spring, plots were treated with herbicides 2,4,-D and Prowl $-\mathrm{H}_{2} \mathrm{O}$ (pendimethalin). At Havelock, plots were treated with Finesse and $44.8 \mathrm{~kg} / \mathrm{ha}$ of $\mathrm{N}$ at planting, and in the spring, they were treated with Prowl- $\mathrm{H}_{2} \mathrm{O}$ and received another $89.6 \mathrm{~kg} / \mathrm{ha}$ of $\mathrm{N}$. No fungicides were applied at either location. The waxy breeding lines and waxy and wild-type checks were grown in three randomized complete blocks each year, in $3-\mathrm{m}^{2}$ plots. Grain from each plot was harvested with a small plot combine.

Details of monthly mean temperatures and relative humidity, and rainfall totals from the heading growth stage (Zadoks growth stage 50 to 59 [Zadoks et al. 1974]) through harvest, are given in Supplementary Table S1; daily means for the period of time wheat was most vulnerable to infection are also listed. Head emergence and anthesis occurred 3 to 5 days apart, depending on the temperature. During 2013 and 2014, FHB was at similarly low levels. In 2015, FHB was at epidemic levels at both locations and stripe rust also was observed at Havelock. Because analyses of plant responses and control cultivars were different, results obtained from 2013 and 2014 plantings were designated as "experiment 1," and results from 2015 plantings were designated as "experiment 2."

Analysis of fungi for experiment 1. Collection and identification of Fusarium spp. from internal infections. Previous studies of Fusarium spp. in air samples taken at Mead and Havelock had indicated that $F$. graminearum and Fusarium proliferatum were the dominant species throughout the summer growing season, which included late June and mid-July (Funnell-Harris and Pedersen 2011; FunnellHarris et al. 2017). Subsamples (5 g) from combined (harvestable) grain from each plot were prepared for determination of fungal 
colonization. Grain harvested in 2013 had symptoms similar to black point. Grain harvested in 2014 had no consistent symptoms. There were no noticeable symptoms of FHB in either year. To identify Fusarium spp. from internal infections, grains collected from each plot were surface disinfested by placing 15 to 20 randomly chosen whole grains in a 15-ml conical tube and washing first with $95 \%$ ethanol for $5 \mathrm{~min}$, followed by $1 \%$ sodium hypochlorite with $0.01 \%$ Tween (Sigma-Aldrich, St. Louis, MO) for $15 \mathrm{~min}$, by gently inverting the tubes, and then rinsing three times in sterile purified water (Labconco, Kansas City, MO). The grain samples were dried in a laminar-flow hood, and then 10 grains were placed onto pentachloronitrobenzene (PCNB) agar medium (Nash and Snyder 1962). It was previously determined that as few as five grains per plot can lead to detection of the major Fusarium pathogens of sorghum, as many as 11 different species/genotypes (Funnell-Harris et al. 2010). The percentage of grains with fungal colonies growing onto the medium for each plot was determined. Individual colonies growing from each grain onto the medium were transferred to one-half strength potato dextrose agar (PDA), amended with $100 \mu \mathrm{M}$ ampicillin (SigmaAldrich). Rarely ( $0.1 \%$ of grains), two distinctively different colonies were obtained from an individual grain; in this case both isolates were collected and counted within the appropriate species category. To more easily observe conidiophore and conidial structures, colonies grown on PDA with characteristics consistent with Fusarium spp. were subcultured onto sporulation medium (1.5\% agar with $80 \mathrm{mM}$ potassium chloride; $\mathrm{KCl}$ ), by aseptically cutting an agar block from the edge of a PDA culture, placing onto the center of $\mathrm{KCl}$ medium, and growing 7 to 10 days at room temperature. The combination of colony morphology on PDA and conidiophore and conidial morphology on $\mathrm{KCl}$ was used to determine putative species identification of a given isolate, or it was designated as Fusarium sp. (Leslie and Summerell 2006). Owing to similarities in morphological characteristics and variability in culture of Fusarium spp. (Aoki et al. 2014; Davari et al. 2012), most (over 85\%) morphological identifications were confirmed by molecular techniques. To produce singleconidium-purified cultures, conidia produced from a $\mathrm{KCl}$ culture were gently dislodged using sterile purified water, and then a conidial suspension was streaked onto peptone glucose agar $(1 \%$ glucose, $0.5 \%$ peptone, $7 \mathrm{mM}$ potassium phosphate monobasic, $2 \mathrm{mM}$ magnesium sulfate heptahydrate, and $2.2 \%$ agar) amended with $100 \mu \mathrm{g} / \mathrm{ml}$ of ampicillin and incubated at room temperature for 24

Table 1. The waxy breeding lines with Plant Introduction (PI) designations and pedigrees utilized in this study

\begin{tabular}{|c|c|c|}
\hline Line & PI number ${ }^{\mathbf{Z}}$ & Pedigree \\
\hline NX12Y8186 & PI 677868 & $\begin{array}{l}\text { NX04Y2066/Wesley//99Y1445/ } \\
\text { NuHorizon }\end{array}$ \\
\hline NX12Y8187 & PI 677869 & $\begin{array}{l}\text { NX04Y2066/Wesley//99Y1445/ } \\
\text { NuHorizon }\end{array}$ \\
\hline NX12Y8188 & PI 677870 & $\begin{array}{l}\text { NX04Y2066/Wesley//99Y1445/ } \\
\text { NuHorizon }\end{array}$ \\
\hline NX12Y8190 & PI 677872 & $\begin{array}{l}\text { NX04Y2066/Wesley//99Y1445/ } \\
\text { NuHorizon }\end{array}$ \\
\hline NX12Y8205 & PI 677873 & $\begin{array}{l}\text { NX04Y2066/Wesley//99Y1445/ } \\
\text { NuHorizon }\end{array}$ \\
\hline NX12Y8209 & PI 677874 & $\begin{array}{l}\text { NX04Y2066/Wesley//99Y1445/ } \\
\text { NuHorizon }\end{array}$ \\
\hline NX12Y8210 & PI 677875 & $\begin{array}{l}\text { NX04Y2066/Wesley//99Y1445/ } \\
\text { NuHorizon }\end{array}$ \\
\hline NX12Y8212 & PI 677876 & $\begin{array}{l}\text { NX04Y2066/Wesley//99Y1445/ } \\
\text { NuHorizon }\end{array}$ \\
\hline NX12Y8213 & PI 677877 & $\begin{array}{l}\text { NX04Y2066/Wesley//99Y1445/ } \\
\text { NuHorizon }\end{array}$ \\
\hline NX12Y8214 & PI 677878 & $\begin{array}{l}\text { NX04Y2066/Wesley//99Y1445/ } \\
\text { NuHorizon }\end{array}$ \\
\hline NX12Y8219 & NA & NuDakota//NX04Y2090/NX03Y2115 \\
\hline NX12Y8222 & PI 677881 & NuDakota//NX04Y2090/NX03Y2115 \\
\hline NX12Y8223 & PI677882 & NuDakota//NX04Y2090/NX03Y2115 \\
\hline
\end{tabular}

${ }^{\mathrm{z}} \mathrm{NA}=$ not applicable. In this case, local selection number (line) was utilized in the text and tables. to $28 \mathrm{~h}$. Conidia were examined under a stereoscopic zoom microscope $(25 \times)$ with a high resolution objective (Nikon Instruments, Melville, NY), and an individual germinating conidium was aseptically transferred to PDA using a surface disinfested scalpel; three germlings were transferred per isolate. Cultures were incubated at room temperature for 10 to 14 days, at which time the colony morphologies of single-conidium-purified cultures were compared with that of the original isolate. Single-conidium-pure isolates were stored as previously described (Funnell-Harris et al. 2013). Briefly, conidial suspensions prepared in sterile skim milk were stored on sterile silica gel (Windels et al. 1988) at $4^{\circ} \mathrm{C}$; conidial suspensions in sterile purified water added to an equal volume of $80 \%$ glycerol in cryovials were stored at $-80^{\circ} \mathrm{C}$; and conidial suspensions were aseptically streaked onto PDA slants, grown 3 to 5 days at room temperature, and then stored at $4{ }^{\circ} \mathrm{C}$. Amplification, sequencing, and comparison of sequences in FUSARIUM-ID were conducted on DNA from single-conidium-pure isolates. Each isolate was grown in glucoseasparagine liquid medium (VanEtten and Bateman 1971) by shaking $(150 \mathrm{rpm})$ at room temperature 5 to 6 days and then filtered $(70 \mathrm{~mm}$ no. 2 Whatman qualitative filter paper; Westnet, Canton, MA) gently under vacuum to collect the mycelium. Mycelium was lyophilized and ground, and then DNA was extracted using the protocol of Lee and Taylor (1990). Polymerase chain reaction (PCR) amplification was performed using primers for the $5^{\prime}$ region of the translation elongation factor 1- $\alpha$ (TEF) gene, ef1 (forward primer; $5^{\prime}$-ATGGGT AAGGA(A/G)GACAAGAC-3') and ef2 (reverse primer; 5'-GGA (G/A)GTACCAGT(G/C)ATCATGTT-3'), and the previously published reaction mixture and conditions (Geiser et al. 2004). Amplification products were either column purified or gel purified using the Amicon Ultra-015 Centrifugal Filter Device (Millipore, Billerica, MA) or the E.Z.N.A. Ultra-Sep Gel Extraction Kit (Omega Biotek, Norcross, GA), respectively. Purified amplification products were sequenced using the same primers as for amplification (Eton Bioscience, San Diego, CA), and sequences from opposite strands were assembled using Sequencher 5.4.1 (Gene Codes Corp., Ann Arbor, $\mathrm{MI}$ ), and consensus $T E F$ sequences were compared with those in the FUSARIUM-ID database (http://www.fusariumdb.org/index. php) (Geiser et al. 2004). Sequences were deposited in GenBank, accession numbers MG826853 through MG826912.

Collection and identification of surface and internal infections of grain by Fusarium spp. Grain grown and collected from plots, as described above, was aseptically applied directly to the surface of

Table 2. Checks with local name, Plant Introduction (PI) number, and waxy phenotype utilized in this study

\begin{tabular}{llc}
\hline Local name & PI number & Waxy phenotype \\
\hline Mattern* & PI 665947 & waxy \\
Alice & PI 644223 & Wild-type \\
Camelot & PI 653832 & Wild-type \\
Goodstreak & PI 632434 & Wild-type \\
Infinity CL & PI 639922 & Wild-type \\
Jagalene & PI 631376 & Wild-type \\
Mace* & PI 651043 & Wild-type \\
McGill & PI 659689 & Wild-type \\
Millennium & PI 613099 & Wild-type \\
NE06545 & PI 667038 & Wild-type \\
NI08708 & NA & Wild-type \\
NW07505 & NA & Wild-type \\
Nuplains & PI 605741 & Wild-type \\
Overland* & PI 647959 & Wild-type \\
Pronghorn & PI 593047 & Wild-type \\
Robidoux & PI 659690 & Wild-type \\
Settler CL* & PI 653833 & Wild-type \\
Tam 111 & PI 631352 & Wild-type \\
Wesley & PI 605742 & Wild-type \\
\hline
\end{tabular}

${ }^{y}$ All checks listed were grown during 2013 and 2014. Checks grown during 2015 are indicated with an asterisk.

${ }^{\mathrm{z}} \mathrm{NA}=$ not applicable. In these cases, local selection number was utilized in the text and tables. 
PCNB agar without prior disinfestation. This indicated not only internal infections but those on the surface that could be removed or destroyed by the disinfestation treatment. Ten randomly chosen grains per plot were applied to the medium. Collection of fungi grown from grain on PCNB agar was as described above. Grains with fungal colonies having characteristics indicative of Fusarium spp. were enumerated, and the percentage of grains with Fusarium contamination per plot was determined. Fungal colonies with characteristics consistent with $F$. graminearum grown on PDA were counted by comparing with known $F$. graminearum isolates, and the percentage of grain with isolates that had characteristics similar to $F$. graminearum per plot was also determined. All other Fusarium isolates determined unlikely to be $F$. graminearum were grouped together as "other Fusarium spp.," and the number of grains per plot containing such isolates was determined.

Analyses of disease responses for experiment 2. The waxy breeding lines (Table 1), the waxy cultivar Mattern (check), and three wildtype cultivars (Table 2) were planted at two locations in Mead and Lincoln, NE, during 2015, as previously described. A timely epidemic allowed assessment of response of these lines to FHB under high disease pressure. Because FHB disease severity, DON levels, and percent FDK were high, it was likely that most Fusarium isolates would be F. graminearum (Markell and Francl 2003; Panthi et al. 2014).

FHB disease severity. Disease severity was assessed on a "per plot" basis and visually scored using a 1 to 10 linear scale of the proportion of bleached spikelets per head, with 1 being no evidence of disease and 10 being highly susceptible (96 to 100\%). Plots were scored approximately 27 (Havelock) or 30 (Mead) days after head emergence.

$F D K$. Seeds with obvious symptoms similar to $F$. graminearum infection (white, chalky, shriveled, and sometimes with a pink tint owing to the fungus) were separated from apparently healthy kernels by flotation in water (Johnson and Beemer 1977). This separation method relies on the fact that FDK, less dense than healthy seed, will, when immersed in water, float to the surface, whereas healthy seeds will sink. Additional separation by hand was performed in a few samples when smaller healthy seeds floated to the surface. To perform this separation technique, a tub was fitted with a colander and, within the colander, a plastic cylinder. The tub and cylinder were filled with purified water, and the seeds from one plot were placed within the cylinder. The seeds were agitated using a glass stir rod to ensure they were well separated. A mesh filter screen was used to catch the FDK and place them on paper toweling in a tray. The healthy seeds were lifted from the water within the colander and placed on a separate paper towel-lined tray. The seeds were dried at $50^{\circ} \mathrm{C}$ and then checked, and further hand separation was performed as needed. The seeds were placed into separate envelopes, and the drying was continued at $40^{\circ} \mathrm{C}$ overnight. The dry seeds were counted using an electronic seed counter. Total seeds ranging from 1,686 to 3,027 were counted for each of 102 plots. The proportion of seeds from each plot with evidence of apparent $F$. graminearum damage was determined.

Analysis of mycotoxins. Grain subsamples from each plot (20 g) were ground using the Cyclone Lab Sample Mill (Udy Corporation, Fort Collins, CO), individually packaged, and then sent to the North Dakota State University Diagnostic Laboratory (https://www.vdl. ndsu.edu/) for analysis of the mycotoxins DON, 3-acetyldeoxynivalenol (3-ADON), 15-acetyldeoxynivalenol (15-ADON), and nivalenol using gas chromatography with electron capture detection. Plots from 2013 and 2014 had grain with low but detectable levels $(\geq 0.50 \mu \mathrm{g} / \mathrm{g})$ of DON, whereas DON and 15-ADON were detected in 2015 grain. For samples with undetectable amounts (below $0.50 \mu \mathrm{g} / \mathrm{g}$ ), the value 0.49 was used for calculations.

Statistical analyses. Analyses of Fusarium spp. from internal infections of grain (experiment 1). To calculate mean percentages of surface-disinfested grain with internal infections, there were two plant phenotypes (14 waxy lines and 18 wild-type lines), 10 grains per plot, and three randomized complete blocks per year for 2 years (2013 and 2014). Total numbers of waxy grains with Fusarium spp. was compared with total wild-type grains using a $\chi^{2}$ test using the PROC FREQ procedure of SAS/STAT software (SAS 2013). The ratios of isolates from different species and species complexes were compared across all waxy lines and all wild-type lines using a $\chi^{2}$ test with the ratios of different Fusarium species and species complexes in the wild-type considered as "expected." Pairwise comparisons of numbers of individual Fusarium spp. or species complexes collected from waxy grain with that from wild-type were also conducted with $\chi^{2}$. In this case, the EXACT statement in PROC FREQ was used to alleviate concerns about asymptotic assumptions not being met. For each Fusarium species and species complex detected in waxy grain, a comparison was made with those obtained from wild-type grain, which was considered "expected." Additionally, for each species within the Fusarium incarnatum- $F$. equiseti species complex (FIESC), the proportion of isolates that were from each plant phenotype (waxy and wild-type) was determined and $\chi^{2}$ was again performed considering wild-type as "expected." As described before, pairwise comparisons were made by comparing the number in each species or species complex within FIESC detected in waxy grain with the number in wild-type using $\chi^{2}$. Additionally, $\chi^{2}$ was used to compare total numbers of Fusarium spp. in each line with the mean from all wild-type lines, which was considered "expected."

Analysis of surface and internal infections of grain by Fusarium spp. from 2013 and 2014 plots (experiment 1). Mean percentages of contaminated grain between waxy and wild-type lines were analyzed with $\chi^{2}$ tests as previously described. Percentages of these grain isolates that had characteristics similar to $F$. graminearum for each plant phenotype (waxy and wild-type), and those that were other Fusarium spp., were determined, and $\chi^{2}$ was again performed, with percentages of each for wild-type grain considered "expected". Also using $\chi^{2}$, comparisons of mean grain contaminated with Fusarium spp. with colony characteristics similar to $F$. graminearum, or all other Fusarium spp. from each individual line (waxy and wildtype), were compared with means obtained from all wild-type lines ("expected"). The mean numbers from each individual line contaminated with $F$. graminearum-like or other Fusarium spp. were also compared with the mean from the known moderately resistant wild-type line, Overland, again, using $\chi^{2}$. Correlations of grains infected by colonies with morphological characteristics similar to $F$. graminearum and total Fusarium spp. or other Fusarium spp. were compared using PROC CORR of SAS/STAT software (SAS 2013).

Analysis of FHB severity and FDK from experiment 2. Comparisons of mean FHB severity ratings and mean proportions of FDK were conducted using PROC MIXED of SAS/STAT software (SAS 2013). There were three randomized complete blocks at each location, two locations, 14 waxy lines, and three wild-type lines. Means across each plant phenotype (waxy or wild-type) or means for each plant line (17) were compared. Replication and location were considered random effects, whereas grain phenotype was the sole fixed effect. In the MODEL statement, the DDFM = KR option was specified to calculate denominator degrees of freedom using the Kenward-Roger method (Kenward and Roger 1997). In the text and tables, means are expressed as least squares means followed by the standard error.

Analyses of mycotoxins. To compare mean DON (2013 and 2014, or 2015) and 15-ADON (2015 only) levels between the two plant phenotypes (wild-type and waxy) for the combined data, PROC MIXED of SAS/STAT software was utilized (SAS 2013). A combined analysis of DON for years 2013 and 2014 was conducted with 18 wild-type and 14 waxy lines, in three replicate blocks in each of the two years. DON and 15-ADON analyses for year 2015 were conducted separately, with three wild-type and 14 waxy lines, three replicate blocks per location, and two locations. Replication and, in the case of 2015 location, were considered random effects. Grain phenotype (for 2013 and 2014, and 2015) and year (for 2013 and 2014) were treated as fixed effects. In the MODEL statement, the DDFM $=$ KR option was specified to calculate denominator degrees of freedom using the Kenward-Roger method (Kenward and Roger 1997). In the text and tables, means are expressed as least squares means followed by the standard error. DON (2013 and 2014, and 2015) and 15-ADON (2015 only) measurements for each individual line also were compared using PROC MIXED. Correlations of numbers of internal and surface infections by Fusarium spp. with colony characteristics consistent with $F$. graminearum or DON levels (2013 
and 2104) and correlations of disease ratings with FDK or DON or 15-ADON levels (2015) were conducted using PROC CORR of SAS/STAT software (SAS 2013).

\section{Results}

Experiment 1. Internal infections by Fusarium spp. from waxy and wild-type grain as determined by surface disinfestation of grain. In 2013 and 2014, trace to low field levels of FHB were observed. Neither field disease severity ratings nor determination of FDK to assess infection levels would have been informative (Koch et al. 2006), and external FHB infection was not apparent. Therefore, grain was assessed for total infection levels by Fusarium spp., including $F$. graminearum. Across all waxy and wild-type lines, there was no significant difference in the percent of waxy and wild-type grain with internal contamination with Fusarium spp. (Fig. 1A). When comparing the mean of each individual line (waxy or wild-type),

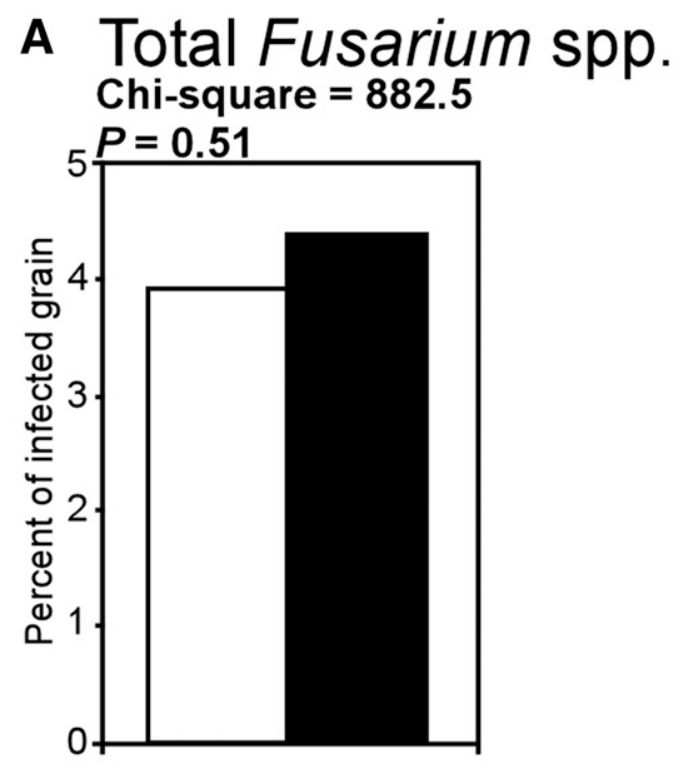

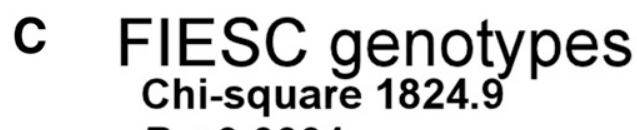

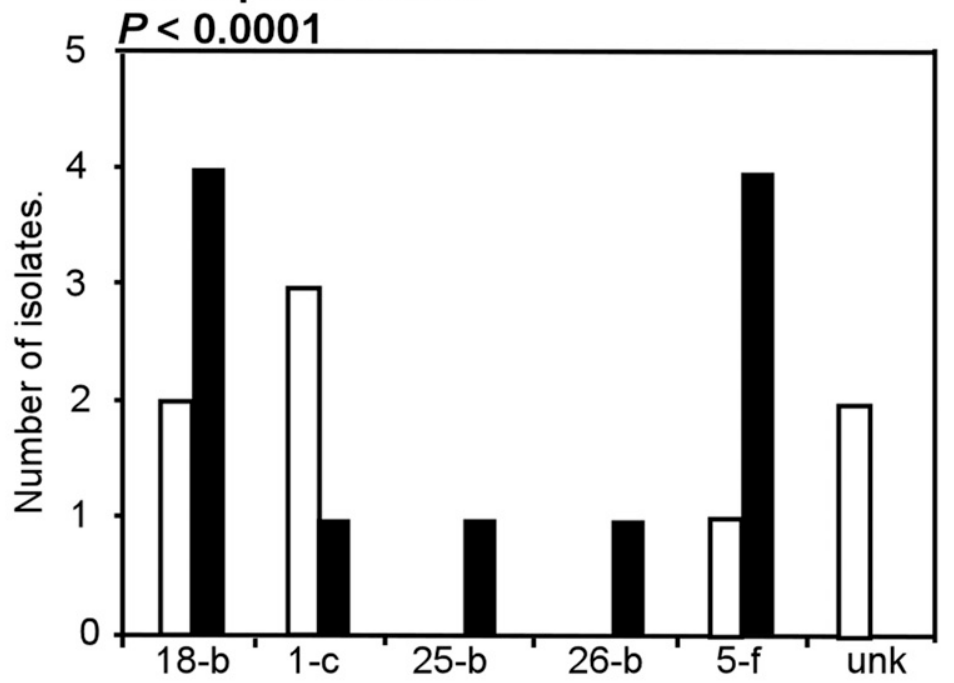

\section{B Fusarium species or species complex}

\section{Chi-square 1062.3}

$P<0.0001$

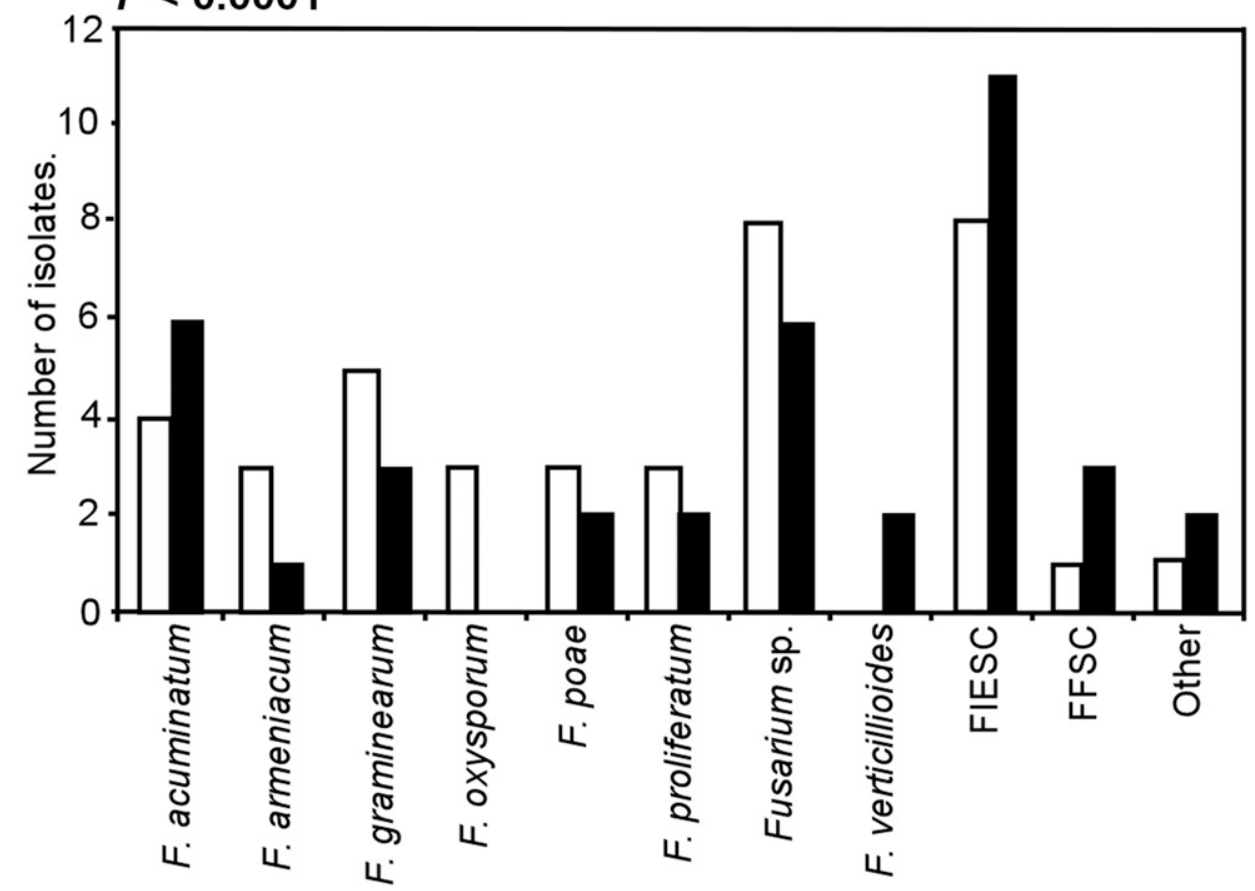

Grain genotype:

Wild-type

waxy

Fig. 1. Fusarium spp. grown from surface-disinfested waxy and wild-type grain onto a semiselective medium, indicating internal infection. A, Percent of waxy and wild-type grain infected by Fusarium species. $\chi^{2}$ analysis compared means of percent from waxy grain with wild-type ("expected"). B, Numbers of isolates from waxy and wild-type grain for each Fusarium species or species complex identified using morphological and molecular techniques. Members of the F. incarnatum-F. equiseti species complex are denoted as "FIESC"; members of the Fusarium fujikuroi species complex unable to be identified to species are denoted as "FFSC"; other isolates unable to be identified to species are denoted as "Fusarium sp."; and species each only detected once (wild-type grain: $F$. pseudonygamai; waxy grain: F. chlamydosporum, $F$. lateritium, and $F$. scirpi) were grouped together and denoted as "Other." Proportions of isolates in each Fusarium group from waxy grain were compared with those from wild-type ("expected") by $\chi^{2}$. C, Numbers of isolates identified in each FIESC genotype isolated from waxy and wild-type grain. $\chi^{2}$ was performed to compare proportions of each FIESC genotype from waxy with those detected in wild-type ("expected"). 
waxy cultivar Mattern and wild-type cultivar Wesley each had mean infection rates of $10.00 \%$, which was significantly higher than the mean of all wild-type lines $(X=3.94 \% ; P=0.02)$. The waxy breeding line PI 677876 and the wild-type cultivars Camelot and Millennium

Table 3. Percent of all Fusarium spp., Fusarium graminearum-like, and all other Fusarium spp. contaminating non-surface-disinfested grains from naturally infected waxy breeding lines, the waxy cultivar Mattern, and wild-type lines $^{\mathrm{z}}$

\begin{tabular}{lrcrrr}
\hline & \multicolumn{3}{c}{$\begin{array}{l}\text { Mean percent } \\
\text { infected grain }\end{array}$} & & \\
\cline { 2 - 3 } Fungal category & waxy & Wild-type & & $\boldsymbol{X}^{\mathbf{2}}$ & \multicolumn{1}{c}{$\boldsymbol{P}$} \\
\hline Total Fusarium spp. & 54.1 & 47.0 & 3.7 & $<0.01$ \\
F. graminearum-like & 4.5 & 3.4 & 904.7 & 0.08 \\
Other Fusarium spp. & 50.0 & 42.5 & 23.4 & $<0.01$ \\
\hline
\end{tabular}

${ }^{\mathrm{z}}$ Grain was aseptically placed onto semiselective medium for Fusarium spp. also had relatively large proportions of grain with internal infections by Fusarium species $(8.33 \% ; P=0.08)$, although not significantly different from the mean of all wild-type lines. All other lines (waxy and wild-type) had mean percentages of infected grain in the range of 0.00 to $6.67 \%$, also not significantly different from the mean across all wild-type (Supplementary Table S2). Seventy-seven Fusarium isolates were collected and identified to species using morphological and/or molecular techniques. The $\chi^{2}$ analysis, using the ratios of species found in wild-type lines as "expected," showed that the proportions of isolates from each species or species complex found in the waxy grains was significantly different (Fig. 1B), indicating that the ratios of different fungi within waxy grain were different from those in the wild-type cultivars chosen for this study. However, pairwise comparison of each species or species complex in waxy versus wild-type grain did not indicate one or a few Fusarium species that had significantly different infection rates of waxy or wild-type grain. Specifically, there was no significant difference between $F$. graminearum-infected waxy and wild-type grain $(P=0.73)$, and total

Table 4. Mean percent of grain infected by Fusarium graminearum or other Fusarium species as a result of superficial and internal infections occurring during 2013 and 2014 and mean levels of deoxynivalenol (DON) $(\mu \mathrm{g} / \mathrm{g})$ in nondisinfested grain from individual waxy breeding lines, the waxy check, and wild-type checks $^{\mathrm{x}}$

\begin{tabular}{|c|c|c|c|c|c|c|c|}
\hline \multirow[b]{2}{*}{ Line } & \multicolumn{6}{|c|}{ Infected grain $(\%)^{y}$} & \multirow[b]{2}{*}{ DON $(\mu g / g)^{2}$} \\
\hline & F. gram. & $P_{\mathrm{WT}}$ & $P_{\text {OV }}$ & Other Fus. spp. & $P_{\mathrm{WT}}$ & $P_{\text {OV }}$ & \\
\hline \multicolumn{8}{|c|}{ waxy breeding lines } \\
\hline PI 677868 & 5.0 & 0.48 & 0.74 & 53.3 & 0.09 & 0.84 & $0.813 \mathrm{ab}$ \\
\hline PI 677869 & 5.0 & 0.48 & 0.74 & 50.0 & 0.24 & 0.76 & $0.508 \mathrm{e}$ \\
\hline PI 677870 & 0.0 & 0.15 & 0.05 & 61.7 & $<0.01$ & 0.13 & $0.895 \mathrm{a}$ \\
\hline PI 677872 & 8.3 & 0.03 & 0.45 & 36.7 & 0.36 & 0.02 & 0.645 cde \\
\hline PI 677873 & 3.3 & 0.99 & 0.38 & 56.7 & 0.03 & 0.47 & $0.566 \mathrm{de}$ \\
\hline PI 677874 & 11.7 & $<0.01$ & 0.06 & 41.7 & 0.90 & 0.11 & $0.508 \mathrm{e}$ \\
\hline PI 677875 & 3.3 & 0.99 & 0.38 & 45.0 & 0.70 & 0.28 & $0.543 \mathrm{cde}$ \\
\hline PI 677876 & 1.7 & 0.46 & 0.16 & 71.7 & $<0.01$ & $<0.01$ & $0.510 \mathrm{e}$ \\
\hline PI 677877 & 1.7 & 0.46 & 0.16 & 73.3 & $<0.01$ & $<0.01$ & $0.490 \mathrm{e}$ \\
\hline PI 677878 & 2.0 & 0.59 & 0.23 & 44.0 & 0.83 & 0.26 & $0.525 \mathrm{de}$ \\
\hline NX12Y8219 & 7.0 & 0.19 & 0.79 & 47.5 & 0.52 & 0.57 & $0.520 \mathrm{de}$ \\
\hline PI 677881 & 10.0 & $<0.01$ & 0.23 & 40.0 & 0.72 & 0.09 & 0.578 cde \\
\hline PI 677882 & 3.3 & 0.99 & 0.38 & 40.0 & 0.70 & 0.06 & 0.597 cde \\
\hline \multicolumn{8}{|l|}{ waxy check } \\
\hline Mattern & 1.7 & 0.46 & 0.16 & 35.0 & 0.24 & $<0.01$ & $0.678 \mathrm{bcd}$ \\
\hline \multicolumn{8}{|l|}{ Wild-type checks } \\
\hline Alice & 8.3 & 0.03 & 0.45 & 46.7 & 0.51 & 0.41 & $0.490 \mathrm{e}$ \\
\hline Camelot & 0.0 & 0.15 & 0.05 & 45.0 & 0.70 & 0.28 & $0.508 \mathrm{e}$ \\
\hline Goodstreak & 0.0 & 0.15 & 0.05 & 38.3 & 0.51 & 0.03 & $0.490 \mathrm{e}$ \\
\hline Infinity CL & 5.0 & 0.48 & 0.74 & 33.3 & 0.15 & $<0.01$ & $0.490 \mathrm{e}$ \\
\hline Jagalene & 6.7 & 0.16 & 0.83 & 40.0 & 0.70 & 0.06 & $0.542 \mathrm{de}$ \\
\hline Mace & 6.0 & 0.30 & 1.00 & 30.0 & 0.07 & $<0.01$ & $0.490 \mathrm{e}$ \\
\hline McGill & 0.0 & 0.19 & 0.07 & 30.0 & 0.07 & $<0.01$ & $0.490 \mathrm{e}$ \\
\hline Millennium & 1.7 & 0.46 & 0.16 & 46.7 & 0.51 & 0.41 & $0.490 \mathrm{e}$ \\
\hline NI08708 & 6.7 & 0.16 & 0.83 & 63.3 & $<0.01$ & 0.08 & $0.710 \mathrm{bc}$ \\
\hline NW07505 & 2.0 & 0.59 & 0.23 & 56.0 & 0.05 & 0.57 & $0.490 \mathrm{e}$ \\
\hline Nuplains & 3.3 & 0.99 & 0.38 & 40.0 & 0.70 & 0.06 & 0.645 cde \\
\hline Overland & 6.0 & 0.30 & $\ldots$ & 52.0 & 0.17 & $\ldots$ & $0.490 \mathrm{e}$ \\
\hline PI 631352 & 1.7 & 0.46 & 0.16 & 35.0 & 0.24 & $<0.01$ & $0.508 \mathrm{e}$ \\
\hline PI 667038 & 6.7 & 0.16 & 0.83 & 43.3 & 0.90 & 0.18 & $0.492 \mathrm{e}$ \\
\hline Pronghorn & 0.0 & 0.15 & 0.05 & 33.3 & 0.15 & $<0.01$ & $0.490 \mathrm{e}$ \\
\hline Robidoux & 0.0 & 0.15 & 0.05 & 50.0 & 0.24 & 0.76 & $0.528 \mathrm{de}$ \\
\hline Settler CL & 3.3 & 0.99 & 0.38 & 33.3 & 0.15 & $<0.01$ & $0.490 \mathrm{e}$ \\
\hline Wesley & 3.3 & 0.99 & 0.38 & 48.3 & 0.36 & 0.57 & 0.577 cde \\
\hline
\end{tabular}

${ }^{x}$ Breeding lines and checks were grown during 2013 and 2014, three replications per year. Subsamples of harvested grain from each plot were made for determination of fungal colonization and for mycotoxin analysis. DON was the only mycotoxin detected during both years.

y Fusarium spp. colonization was determined by directly applying grain onto a semiselective medium for Fusarium spp. Percent of seeds that were infected by $F$. graminearum (F. gram.) and by all other Fusarium spp. (other Fus. spp.) were determined for each plot. Means were determined for each line, and for all wildtype lines, and then $\chi^{2}$ tests were conducted using PROC FREQ (SAS 2013), comparing each line back to the mean $(x=0.337)$ of all wild-type lines $\left(P_{\mathrm{WT}}\right)$. Additionally, means from each line were also compared with the mean of the Fusarium head blight moderately resistant cultivar, Overland $\left(P_{\text {Ov }}\right)$.

${ }^{\mathrm{z}}$ Ground grain subsamples were analyzed for mycotoxins at North Dakota State University Diagnostic Laboratory (https://www.vdl.ndsu.edu/). For samples with undetectable amounts, the value 0.49 was used for calculations. To compare mean DON levels between all lines, PROC MIXED of SAS/STAT software was utilized (SAS 2013). Values with different letters are significantly different at $P \leq 0.05$. Standard errors for nearly all lines were 0.057 except for PI 677870 , PI 677875, NX12Y8219, Mace, McGill, and Settler CL, which were 0.069. 
internal infection by $F$. graminearum was only $10.4 \%$ of the total Fusarium spp. obtained from surface-disinfested grain. The FIESC was the largest group (24.7\%) among all the isolates (Fig. 1B), with five known genotypes and two isolates from wild-type grain with unknown genotypes. The ratios of isolates in each FIESC genotype, or the two unknown FIESC genotypes considered together, for isolates in waxy grain, were subjected to $\chi^{2}$ analyses using ratios of wild-type grain as "expected." There was a significant difference in the ratios of the different FIESC genotypes isolated from waxy grain (Fig. 1C). Pairwise comparisons within each FIESC genotype did not show significant differences between waxy and wild-type.

Surface and internal Fusarium spp. colonization on waxy and wild-type grain. The percentage of grain with Fusarium-like colonies growing onto the surface of the medium was significantly greater for waxy than for wild-type (Table 3 ). These colonies were subcultured onto PDA and, based on morphological colony characteristics, were assigned to one of two groups: those similar to $F$. graminearum and all other Fusarium spp. The percent of waxy grain with $F$. graminearum-like colonies was similar to that of the wild-type, whereas waxy grains with all other Fusarium spp., as determined by selection on PCNB medium, were significantly greater than wild-type (Table 3). For surface and internal infections, as determined in nondisinfested grain, individual lines were compared with the mean of all wild-type lines using $\chi^{2}$. Among the waxy breeding lines, only three had $F$. graminearum colonization of nondisinfested grain significantly greater than the mean of the wild-type lines during the 2013 and 2014 growing seasons: PI 677872, PI 677874, and PI 677881 (Table 4). All other waxy breeding lines, and the waxy check (Mattern), had levels of $F$. graminearum-like infection not significantly different from the mean of the wild-type lines. Among the wildtype lines, only the cultivar Alice had a significantly greater percent of grain infected with $F$. graminearum-like isolates than the mean of the wild-type lines. Among the waxy breeding lines, four (PI 677870, PI 677873, PI 677876, and PI 677877) had infections by other Fusarium spp. significantly greater than the mean across all wild-type (Table 4), whereas two wild-type lines, NI08708 and NW07505, had higher levels than the wild-type mean. Means of each line also were compared with the known FHB moderately resistant wildtype cultivar, Overland. The waxy breeding line PI 677870 and the wild-type cultivars Camelot, Goodstreak, Pronghorn, and Robidoux had percent $F$. graminearum-like grains significantly less than that of Overland (Table 4). All other waxy breeding lines, Mattern, and wildtype lines had percent $F$. graminearum-like infected grain similar to Overland. For percent of grains infected with all other Fusarium spp., one waxy breeding line, PI 677872, and six wild-type cultivars (Infinity CL, Mace, McGill, PI 631352, Pronghorn, and Settler CL) had means significantly less than that of Overland (Table 4). Two waxy breeding lines, PI 677876 and PI 677877, had mean percent of grains infected with other Fusarium spp. significantly greater than that of Overland. All other lines had levels similar to that of Overland. Correlation analysis demonstrated there was no correlation between the total numbers of $F$. graminearum-like infected grain and total $F u s a$ rium spp. or other Fusarium spp. ( $P \geq 0.67)$.

DON levels in nondisinfested grain from waxy and wild-type lines. There was a significant difference in mean DON levels across all lines between the two years $2013(0.614 \pm 0.021 \mu \mathrm{g} / \mathrm{g})$ and 2014 $(0.493 \pm 0.002 \mu \mathrm{g} / \mathrm{g})(P<0.01)$; the mean DON level for 2014

Table 5. Deoxynivalenol (DON) levels ( $\mu \mathrm{g} / \mathrm{g})$ in waxy and wild-type grain grown in 2013 and $2014^{z}$

\begin{tabular}{lcc}
\hline & \multicolumn{2}{c}{ DON $(\mu \mathrm{g} / \mathrm{g})$} \\
\cline { 2 - 3 } Year & waxy & Wild-type \\
\hline 2013 & $0.667^{*} \pm 0.036$ & $0.559 \pm 0.032$ \\
2014 & $0.500^{*} \pm 0.003$ & $0.490 \pm 0.003$ \\
\hline
\end{tabular}

${ }^{\mathrm{z}}$ To compare mean DON levels between the two plant phenotypes (wild-type and waxy), PROC MIXED of SAS/STAT software was utilized (SAS 2013). Means and standard errors are shown. Asterisks indicate that levels from waxy grain were significantly greater $(P=0.02)$ than those for wild-type. was in the undetectable range. Mean DON levels across years were significantly different for waxy $(0.591 \pm 0.019)$ and wild-type $(0.524 \pm 0.017)$ grain $(P=0.01)$. Interaction of grain phenotype and year also was significant $(P=0.03)$. Mean DON levels for waxy and wild-type grains are shown in Table 5; for each year, the mean DON level for waxy grain was significantly greater than that for wild-type $(P=0.02)$. Correlation analyses of numbers of internal and surface colonization by $F$. graminearum-like isolates with DON showed no significant association $(r=-0.23 ; P=0.43)$. The highest mean DON level across both years was found in the waxy breeding line PI 677870; this was significantly greater than all the checks, including Mattern, and all the other waxy breeding lines, except PI 677868 (Table 4). Most of the wild-type lines (Alice, Goodstreak, Infinity CL, Mace, McGill, Millennium, NW07505, Overland, PI 667038, and Settler CL) and the waxy breeding line PI 677877 had mean DON levels in the undetectable range.

Experiment 2. FHB severity during the 2015 epidemic. There was no significant difference in mean disease ratings when comparing across all waxy $(7.25 \pm 1.61)$ and wild-type $(7.78 \pm 1.60)$ lines $(P=0.09)$. Comparison of individual lines showed that the waxy cultivar Mattern and the waxy breeding lines PI 677869, PI 677870, PI 677881, and PI 677882 had similarly high levels of FHB severity, in the range of 8.5 to 9.3 (Table 6). On the other hand, seven waxy breeding lines had FHB severities significantly less than that of Mattern and not significantly different from that of the moderately resistant wild-type cultivar, Overland.

FDK resulting from the 2015 FHB epidemic. There were no significant differences between waxy (0.184) and wild-type (0.190) $(\mathrm{SE}=$ $0.04 ; P=0.75$ ) with respect to proportions of FDK. Seven waxy breeding lines, and the wild-type cultivars Mace and Settler CL, had FDK similar to that of Mattern (Table 6). Six waxy breeding lines had FDK significantly less than that of Mattern, and among them, PI 677873, PI 677874, PI 677876, PI677877, and PI 677878 all had FDK similar to the moderately resistant wild-type cultivar, Overland $(P \geq 0.09)$. Correlation of FHB severity and FDK was significant $(r=0.74 ; P<0.01)$.

DON and 15-ADON levels in grain from waxy and wild-type lines resulting from the $2015 \mathrm{FHB}$ epidemic. Of the four mycotoxins (DON, 3-ADON, 15-ADON, and nivalenol) evaluated in the 2015 grain, DON and 15-ADON were detected in 100 and $81.6 \%$ of the plots, respectively. Comparing the means across all waxy lines with those across wild-type lines showed there were significant differences in the levels of DON and 15-ADON in the waxy lines (Table 7). The mean DON level in Mattern grain was significantly greater than all other lines in the study $(P<0.01)$, whereas Mattern, PI 677868, PI 677869, and PI 677780 all had similarly high levels of 15-ADON (Table 6). The waxy breeding lines PI 677873, PI 677874, PI 677876, PI 677877, and PI677878, and the wild-type cultivars Mace and Settler CL, all had DON levels not significantly different from the moderately resistant wild-type cultivar, Overland $(P \geq$ 0.07), and these, along with PI677872 and PI 677882, had 15-ADON levels not significantly different from that of Overland $(P \geq 0.06)$. The 15-ADON level in Overland grain was in the undetectable range (Table 6). Correlation of FHB severity with DON $(r=0.49 ; P<0.01)$ or $15-\mathrm{ADON}(r=0.45 ; P<0.01)$ was significant.

\section{Discussion}

Breeding lines that are waxy had been developed to increase the genetic variation for waxy cultivation in the Great Plains and to broaden the usability of wheat overall for modified food starches and specialty baked goods (Graybosch 1998; Graybosch et al. 2018; Kowalski et al. 2017). This region of the United States experiences moderate to severe FHB during intermittent growing seasons (McMullen et al. 2012; Panthi et al. 2014; Shah et al. 2013). Observations of the waxy cultivar Mattern (designated as NX04Y2107) during the USDA-ARS coordinated NRPN, and our observations during other years when grown at Mead, NE, indicated that Mattern appeared to be highly susceptible to this and other grain diseases; therefore, it was imperative to assess responses of the waxy breeding lines to naturally occurring Fusarium infections, including by 
F. graminearum. Previous studies of Fusarium species from air samples taken over research fields at Mead, NE, that included wheat and other grains indicated that $F$. graminearum could be commonly found at critical times during the growing season (Funnell-Harris and Pedersen 2011; Funnell-Harris et al. 2017) depending on environmental conditions conducive to increased sporulation and infection (Duveiller et al. 2007; Leplat et al. 2013). For the three years in which the waxy breeding lines were grown, FHB was observed at trace and low levels (2013 and 2014) and at profoundly high, epidemic levels (2015), allowing for assessment of the reaction of these lines to various natural infection levels by Fusarium species and $F$. graminearum.

During experiment 1 conducted in the years 2013 and 2014, internal infections by Fusarium species, as indicated by fungal growth from surface disinfested grain, were not significantly different (Fig. 1A). However, total external and internal infections by Fusarium species, as indicated by direct plating of nondisinfested grain, provided evidence that the waxy grains across different lines had higher levels of Fusarium species infections than wild-type grains (Table 3). However, mean levels of $F$. graminearum or $F$. graminearum-like infections were not significantly different across waxy and wildtype lines when considering trace to low levels of disease observed in the field. Taken together, these results indicated that in 2013 and 2014, differences in internal and external infections by Fusarium species in waxy and wild-type grain were not owing to $F$. graminearum. Nonetheless, DON levels were significantly higher across waxy compared with the wild-type lines.

For experiment 2, the severe levels of FHB observed in 2015 allowed assessment of the response of the waxy breeding lines, as well as Mattern and wild-type cultivars, to FHB under high disease intensity during natural infection. In this case, the waxy lines had levels of FHB severity and FDK similar to those of the wild-type lines. However, across all waxy lines as compared with all wild-type, and across both locations, DON levels were higher in the waxy lines. The DON values observed (Tables 6 and 7) were similar to or even higher than those in previous studies in which high FHB disease severity was observed, whether artificially inoculated (Kharbikar et al. 2015) or resulting from natural infection (Audenaert et al. 2009).

For a meta-analysis reported in 2005 (Paul et al. 2005) of all available studies (published and unpublished) of FHB in naturally or artificially infested fields, individual studies could show strong positive correlations of disease severity (reported as "index" or IND) or FDK with DON, or no significant correlation, or even negative correlation. Across all studies, the strongest significant and positive correlation was between FDK and DON, but disease severity significantly correlated with DON as well. Since that time, some studies with artificial inoculation reported highly significant correlations between FHB disease severity or FDK and DON (Bonin and Kolb 2009; Burlakoti et al. 2007; Kubo et al. 2014), but not all observed this association (Malbrán et al. 2014), suggesting that a given environment can affect DON production. In the current study, experiment 2 data indicated significant correlations between disease severity and FDK or DON levels following a season of natural infections, but there were no significant differences between waxy and wild-type

Table 7. Mean deoxynivalenol (DON) and 15-acetyldeoxynivalenol (15ADON) levels $(\mu \mathrm{g} / \mathrm{g})$ in grain of waxy (breeding lines and check) and wild-type (checks) lines resulting from an epidemic level of Fusarium graminearum infection $^{\mathrm{z}}$

\begin{tabular}{lcc}
\hline Plant phenotype & DON $(\boldsymbol{\mu g} / \mathbf{g})$ & 15-ADON $(\boldsymbol{\mu g} / \mathbf{g})$ \\
\hline Wild-type & $15.54 \pm 0.76$ & $0.56 \pm 0.02$ \\
waxy & $21.47 \pm 1.07$ & $0.76 \pm 0.03$ \\
$P$ & $<0.01$ & $<0.01$ \\
\hline
\end{tabular}

${ }^{\mathrm{z}}$ Grain samples from each plot were analyzed for the mycotoxins DON and 15-ADON at North Dakota State University Diagnostic Laboratory (https://www.vdl.ndsu.edu/). The differences of least squares means (LSMs) were determined using the PROC MIXED procedure of SAS/STAT software (SAS 2013). LSMs and standard errors are shown.

Table 6. Mean Fusarium head blight (FHB) severity ratings, proportion of Fusarium-damaged kernels (FDK), and deoxynivalenol (DON) and 15-acetyldeoxynivalenol (15-ADON) levels ( $\mu \mathrm{g} / \mathrm{g}$ ) from waxy breeding lines and waxy and wild-type checks as a result of a severe FHB epidemic during 2015 at two locations in eastern Nebraskaw

\begin{tabular}{|c|c|c|c|c|}
\hline \multirow[b]{2}{*}{ Line } & \multirow[b]{2}{*}{ FHB severity ${ }^{x}$} & \multirow[b]{2}{*}{ FDK $^{\mathbf{y}}$} & \multicolumn{2}{|c|}{ Mycotoxins $(\mu \mathrm{g} / \mathrm{g})^{\mathrm{z}}$} \\
\hline & & & DON & 15-ADON \\
\hline \multicolumn{5}{|c|}{ waxy breeding lines } \\
\hline PI 677868 & $7.7 \mathrm{~cd}$ & $0.174 \pm 0.031 \mathrm{bc}$ & $25.90 \mathrm{bcd}$ & $0.98 \mathrm{ab}$ \\
\hline PI 677869 & $8.5 a b c$ & $0.206 \pm 0.031 \mathrm{ab}$ & $26.87 \mathrm{bc}$ & $0.93 a b c$ \\
\hline PI 677870 & $9.0 \mathrm{abc}$ & $0.242 \pm 0.035 \mathrm{a}$ & $28.93 \mathrm{~b}$ & $0.93 \mathrm{abc}$ \\
\hline PI 677872 & $7.5 \mathrm{~cd}$ & $0.257 \pm 0.042 \mathrm{a}$ & $19.73 \mathrm{de}$ & $0.62 \mathrm{def}$ \\
\hline PI 677873 & $4.8 \mathrm{e}$ & $0.116 \pm 0.031$ ef & $15.62 \mathrm{ef}$ & $0.51 \mathrm{f}$ \\
\hline PI 677874 & $5.5 \mathrm{e}$ & $0.140 \pm 0.032 \mathrm{cdef}$ & $13.20 \mathrm{f}$ & $0.54 \mathrm{f}$ \\
\hline PI 677875 & $8.2 \mathrm{bc}$ & $0.176 \pm 0.038$ abcde & $25.48 \mathrm{bcd}$ & $0.83 \mathrm{bcd}$ \\
\hline PI 677876 & $5.2 \mathrm{e}$ & $0.128 \pm 0.036 \mathrm{cdef}$ & $12.92 \mathrm{f}$ & $0.53 \mathrm{f}$ \\
\hline PI 677877 & $5.2 \mathrm{e}$ & $0.119 \pm 0.030$ ef & $13.25 \mathrm{f}$ & $0.51 \mathrm{f}$ \\
\hline PI 677878 & $5.2 \mathrm{e}$ & $0.104 \pm 0.032 \mathrm{f}$ & $16.47 \mathrm{ef}$ & $0.63 \mathrm{def}$ \\
\hline NX12Y8219 & $8.2 \mathrm{bc}$ & $0.235 \pm 0.041 \mathrm{ab}$ & 21.77 cde & $0.90 \mathrm{bc}$ \\
\hline PI 677881 & $9.2 \mathrm{a}$ & $0.239 \pm 0.038 \mathrm{a}$ & $19.80 \mathrm{de}$ & 0.78 bcde \\
\hline PI 677882 & $8.8 \mathrm{ab}$ & $0.228 \pm 0.039 \mathrm{ab}$ & $18.80 \mathrm{e}$ & 0.72 cdef \\
\hline \multicolumn{5}{|l|}{ Checks } \\
\hline \multicolumn{5}{|l|}{ waxy } \\
\hline Mattern & $9.3 \mathrm{a}$ & $0.230 \pm 0.035 \mathrm{a}$ & $41.78 \mathrm{a}$ & $1.15 \mathrm{a}$ \\
\hline \multicolumn{5}{|l|}{ Wild-type } \\
\hline Mace & $8.2 \mathrm{abc}$ & $0.230 \pm 0.038 \mathrm{ab}$ & 15.75 ef & $0.56 \mathrm{ef}$ \\
\hline Overland & $6.2 \mathrm{de}$ & $0.134 \pm 0.030 \mathrm{def}$ & $12.53 \mathrm{f}$ & $0.49 \mathrm{f}$ \\
\hline Settler CL & $8.3 \mathrm{abc}$ & $0.199 \pm 0.039 \mathrm{abcd}$ & $18.33 \mathrm{ef}$ & 0.62 def \\
\hline
\end{tabular}

${ }^{\mathrm{w}}$ Lines were planted in three randomized complete blocks at each location. Disease severity was recorded for each plot, based on a 1 to 10 linear scale. Throughout this table, PROC MIXED of SAS/STAT software (SAS 2013) was used to compare least squares means between lines. Values with different letters are significantly different at $P \leq 0.05$.

x Disease severity was assessed on a "per plot" basis and visually scored using a 1 to 10 linear scale of the proportion of bleached spikelets per head, with 1 being no evidence of disease and 10 being highly susceptible (96 to 100\%). Standard errors (SEs) for PI 677870, PI 677872, PI 677873, PI 677876, PI 677878, Mattern, and Overland were 1.6; all other SEs were 1.5.

y The proportion of grain in each plot with evidence of $F$. graminearum damage was determined.

${ }^{z}$ Ground grain subsamples were analyzed for mycotoxins at North Dakota State University Diagnostic Laboratory (https://www.vdl.ndsu.edu/). For samples with undetectable amounts, the value 0.49 was used for calculations. $\mathrm{DON}$ SE $=3.17 ; 15-\mathrm{ADON} \mathrm{SE}=0.10$. 
for disease severity or FDK. However, in both experiments 1 and 2, DON levels were significantly higher in waxy grain compared with wild-type (Tables 5 and 7). These seemingly contradictory results could be explained by a number of factors. For example, the fungal populations detected during experiment 1 indicated that those infecting the waxy PIs and Mattern were different from those in the wildtype cultivars chosen for these studies. Fusarium spp. other than $F$. graminearum also can produce DON, including those detected as internal infections in experiment 1 , such as $F$. acuminatum, $F$. oxysporum, $F$. poae, $F$. proliferatum, and members of the FIESC (Hubert et al. 2014; Lincy et al. 2011; Marín et al. 2012; Richard et al. 2007); isolates of some of these species may have been included with the "other Fusarium spp." from the internal and external infection screen, a category that was significantly larger in waxy grain than in wild-type (Fig. 1, Table 3). Another possible explanation is the previously observed translocation of DON from crown infections to asymptomatic heads of wheat by $F$. graminearum (Beccari et al. 2018; Covarelli et al. 2012); this explanation would assume that infection or translocation was greater or more efficient, respectively, among waxy lines than wild-type. Although there were no observed seedling diseases during the three years of this study, this phenomenon can occur during asymptomatic infections (Obanor and Chakraborty 2014).

Another possible explanation is that because the basic starch structure is modified in waxy grains, the fungus may be able to utilize additional components for greater DON production. The waxy trait is known to affect structure of the endosperm and of starch granules (Demeke et al. 1999; Kang et al. 2006; Sattler et al. 2009). Because physicochemical, morphological, and structural characteristics are affected in waxy wheat, amylose content is generally inversely proportional to starch digestibility (Shevkani et al. 2017). Partial waxy wheat grains have been shown to have significantly increased levels of mono- and polysaccharides such as sucrose, glucose, maltose, and $\beta$-glucans (Nakamura et al. 2006; Yasui and Ashida 2011). Genes of the $F$. graminearum trichothecene (Tri) biosynthesis pathway that encode for enzymes that produce DON and its acetylated derivatives 3-ADON and 15-ADON, as well as nivalenol and its acetylated derivative 4-acetylnivalenol, can be induced in vitro using different carbon sources. For example, it was shown that Tri5 (encoding for trichodiene synthase) and Tri4 (encoding for a cytochrome P450 mono-oxygenase that hydroxylates trichodiene) are upregulated by sucrose but not glucose (Jiao et al. 2008; Tokai et al. 2007). Because in vitro culture of Fusarium spp. production of DON and other mycotoxins is conducted in media rich in carbohydrates (Jiao et al. 2008; Varga et al. 2015; Vasavada and Hsieh 1987), it is possible that increased availability of sugars, as a result of increased digestibility of waxy starch, could induce greater colonization and DON production by $F$. graminearum in waxy grains than in wild-type. It is likely that multiple factors, perhaps one or more discussed herein, are involved in the relatively high DON levels observed in some waxy lines during high FHB severity.

Nonetheless, this work strongly indicated that among these waxy breeding lines were individual lines having desirable agronomic and quality traits, such as adequate grain and flour protein amounts and no apparent grain yield drag (Graybosch et al. 2018), with responses to $F$. graminearum infection (infection rates and DON levels) similar to elite wild-type cultivars. For experiment 1, with trace and low levels of FHB (2013 and 2014), only three of the 13 lines had significantly higher levels of $F$. graminearum-like contamination, and only two lines had significantly higher levels of DON than most of the wild-type lines (Table 4). All the waxy breeding lines had $F$. graminearum-like infection levels the same or less (PI 677870) than that of the moderately resistant wild-type cultivar, Overland, and most lines (except PI 677870 and PI 677868) had DON levels similar to Overland (Table 4). For experiment 2, with high FHB intensity, five (PI 677873, PI 677874, PI 677876, PI 677877 , and PI 677878) of the waxy breeding lines had severity ratings, percent FDK, and DON and 15-ADON levels significantly lower than means observed in cultivar Mattern, and not significantly different from those of Overland (Table 6). These results indicated that these five lines have great potential for breeding waxy lines with reduced susceptibility to FHB under both low and high disease severity.

Understandably, much attention and effort have been placed on FHB pathogens, but there has been little emphasis on other wheatinfecting Fusarium species that may also impact the response of wheat to FHB (Kosiak et al. 2004; Muthomi et al. 2008). In the present study the wide range of Fusarium spp. other than $F$. graminearum that were detected causing internal infections of the grain (Fig. 1) and the large numbers of other Fusarium spp. recovered from the surface, as well as internally (Tables 3 and 4), suggests that toxins besides DON may be present in wheat samples, such as moniliformin, HT-2, T-2, and diacetoxyscirpenol (Covarelli et al. 2015; Tittlemier et al. 2013). Early infections by other fungi could conceivably reduce subsequent infections by $F$. graminearum (Aureli et al. 2015; Jensen et al. 2016; Kosiak et al. 2004), although an inverse correlation of these infections was not observed in the present work. An unexpected result of the current study was that internal infection ratios of Fusarium species or species complexes were significantly different between the waxy lines and the wild-type lines chosen for this study. Although the waxy trait may have caused differential infection by Fusarium spp., the genetic backgrounds of the waxy lines used, as well as wild-type lines, may also have affected the distribution of Fusarium species in the grain (Funnell and Pedersen 2006; Stack and Pedersen 2003).

In summary, the screening of waxy breeding lines under trace to low levels of FHB allowed for determining response to internal and superficial infections by Fusarium species, including $F$. graminearum (experiment 1). Using surface disinfestation before plating and direct plating of nondisinfested grain onto Fusarium-selective medium allowed determination that lines PI 677876 and PI 677877 were the most resistant to infections by $F$. graminearum and Fusarium spp. similar to $F$. graminearum and had the lowest levels of DON accumulation among the waxy lines tested under these conditions (Fig. 1, Table 4). Analysis of disease response parameters during an FHB epidemic year (experiment 2) confirmed that the same two lines, as well as three more lines (PI 677873, PI 677874, and PI 677878) had responses similar to the moderately resistant wildtype cultivar, Overland. These results provided strong evidence that the waxy PIs would be good candidates for breeding waxy lines with wild-type levels of infection by Fusarium spp. and tolerance to $F$. graminearum. Techniques described in this study, such as the combination of direct plating of grain onto PCNB with assessing DON levels, may have great potential for use in breeding programs for screening materials for reduced FHB disease even under low levels of $F$. graminearum infection. This could be especially important in the Great Plains wheat belt, because natural FHB infestations are intermittent but can be devastating, as in 2015, when they occur (McMullen et al. 2012).

\section{Acknowledgments}

The authors thank W.-B. Shim for valuable discussion; L. Divis and J. Venegas for field operations and collection and processing of grain; and K. Fosler, M. Wilson, T. Osborne, and M. Kilts for laboratory technical assistance.

\section{Literature Cited}

Ahuja, G., Jaiswal, S., Hucl, P., and Chibbar, R. N. 2013. Genome-specific granule-bound starch synthase I (GBSSI) influences starch biochemical and functional characteristics in near-isogenic wheat (Triticum aestivum L.) lines. J. Agric. Food Chem. 61:12129-12138.

Aoki, T., O'Donnell, K., and Geiser, D. M. 2014. Systematics of key phytopathogenic Fusarium species: Current status and future and challenges. J. Gen. Plant Pathol. 80:189-201.

Atanasoff, D. 1920. Fusarium-blight (scab) of wheat and other cereals. J. Agric Res. 20:1-32.

Audenaert, K., Van Broeck, R., Bekaert, B., De Witte, F., Heremans, B., Messens, K., Hofte, M., and Haesaert, G. 2009. Fusarium head blight (FHB) in Flanders: Population diversity, inter-species associations and DON contamination in commercial winter wheat varieties. Eur. J. Plant Pathol. 125:445-458.

Aureli, G., Amoriello, T., Belocchi, A., D’Egidio, M. G., Fornara, M., Melloni, S., and Quaranta, F. 2015. Preliminary survey on the co-occurrence of DON and T2+HT2 toxins in durum wheat in Italy. Cereal Res. Commun. 43 481-491. 
Baenziger, P. S., Rose, D., Santra, D., Guttieri, M., and Xu, L. 2015. Page 49 in: Improving Wheat Varieties for Nebraska: 2014 State Breeding and Quality Evaluation Report. Nebraska Wheat Development, Utilization and Marketing Board, Lincoln.

Baenziger, P. S., Rose, D., Santra, D., and Xu, L. 2014. Page 47 in: Improving Wheat Varieties for Nebraska: 2013 State Breeding and Quality Evaluation Report. Nebraska Wheat Development, Utilization and Marketing Board, Lincoln.

Bateman, G. L., Gutteridge, R. J., Gherbawy, Y., Thomsett, M. A., and Nicholson, P. 2007. Infection of stem bases and grains of winter wheat by Fusarium culmorum and $F$. graminearum and effects of tillage method and maize-stalk residues. Plant Pathol. 56:604-615.

Beccari, G., Prodi, A., Pisi, A., Nipoti, P., Onofri, A., Nicholson, P., Pfohl, K., Karlovsky, P., Gardiner, D. M., and Covarelli, L. 2018. Development of three Fusarium crown rot causal agents and systemic translocation of deoxynivalenol following stem base infection of soft wheat. Plant Pathol. 67: 1055-1065.

BeMiller, J. N. 2009. One hundred years of commercial food carbohydrates in the United States. J. Agric. Food Chem. 57:8125-8129.

Bhattacharya, M., Erazo-Castrejon, S. V., Doehlert, D. C., and McMullen, M. S. 2002. Staling of bread as affected by waxy wheat flour blends. Cereal Chem. 79:178-182.

Bonin, C. M., and Kolb, F. L. 2009. Resistance to Fusarium head blight and kernel damage in winter wheat recombinant inbred line population. Crop Sci. 49: 1304-1312.

Burlakoti, R. R., Estrada, R., Rivera, V. V., Boddeda, A., Secor, G. A., and Adhikari, T. B. 2007. Real-time PCR quantification and mycotoxin production of Fusarium graminearum in wheat inoculated with isolates collected from potato, sugar beet, and wheat. Phytopathology 97:835-841.

Covarelli, L., Beccari, G., Prodi, A., Generotti, F., Meca, G., Juan, C., and Manes, J. 2015. Biosynthesis of beauvericin and enniatins in vitro by wheat Fusarium species and natural grain contamination in an area of central Italy. Food Microbiol. 46:618-626.

Covarelli, L., Beccari, G., Steed, A., and Nicholson, P. 2012. Colonization of soft wheat following infection of the stem base by Fusarium culmorum and translocation of deoxynivalenol to the head. Plant Pathol. 61:1121-1129.

Cowger, C., and Arrellano, C. 2010. Plump kernels with high deoxynivalenol linked to late Gibberella zeae infection and marginal disease conditions in winter wheat. Phytopathology 100:719-728.

Cowger, C., Patton-Ozkurt, J., Brown-Guedira, G., and Perugini, L. 2009. Postanthesis moisture increased Fusarium head blight and deoxynivalenol levels in North Carolina winter wheat. Phytopathology 99:320-327.

Czaban, J., Wroblewska, B., Sulek, A., Mikos, M., Boguszewska, E., Podolska, G., and Nierobca, A. 2015. Colonisation of winter wheat grain by Fusarium spp. and mycotoxin content as dependent on a wheat variety, crop rotation, a crop management system and weather conditions. Food Addit. Contam. Part A 32: 874-910.

Dahl, B., and Wilson, W. W. 2018. Risk premiums due to Fusarium head blight (FHB) in wheat and barley. Agric. Syst. 162:145-153.

Davari, M., van Diepeningen, A. D., Babai-Ahari, A., Arzanlou, M., Najafzadeh, M. J., van der Lee, T. A. J., and de Hoog, G. S. 2012. Rapid identification of Fusarium graminearum species complex using rolling circle amplification (RCA). J. Microbiol. Methods 89:63-70.

Del Ponte, E. M., Fernandes, J. M. C., Pavan, W., and Baethgen, W. E. 2009. A model-based assessment of the impacts of climate variability on Fusarium head blight in southern Brazil. J. Phytopathol. 157:675-681.

Demeke, T., Huel, P., Abdel-Aal, E.-S. M., Baga, M., and Chibbar, R. N. 1999. Biochemical characterization of the wheat waxy A protein and its effect on starch properties. Cereal Chem. 76:694-698.

Duveiller, E., Singh, R. P., and Nicol, J. M. 2007. The challenges of maintaining wheat productivity: Pests, diseases, and potential epidemics. Euphytica 157: 417-430.

Fasahat, P., Rahman, S., and Wickneswari, R. 2014. Genetic controls on starch amylose content in wheat and rice grains. J. Genet. 93:279-292.

Fujita, S., Yamamoto, H., Sugimoto, Y., Morita, N., and Yamamori, M. 1998. Thermal and crystalline properties of waxy wheat (Triticum aestivum L.) starch. J. Cereal Sci. 27:1-5.

Funnell, D. L., and Pedersen, J. F. 2006. Reaction of sorghum lines genetically modified for reduced lignin content to infection by Fusarium and Alternaria spp. Plant Dis. 90:331-338.

Funnell-Harris, D. L., and Pedersen, J. F. 2011. Presence of Fusarium spp. in air and soil associated with sorghum fields. Plant Dis. 95:648-656.

Funnell-Harris, D. L., Pedersen, J. F., and Sattler, S. E. 2010. Alteration in lignin biosynthesis restricts growth of Fusarium spp in brown midrib sorghum. Phytopathology 100:671-681.

Funnell-Harris, D. L., Prom, L. K., and Pedersen, J. F. 2013. Isolation and characterization of the grain mold fungi Cochliobolus and Alternaria spp. from sorghum using semiselective media and DNA sequence analyses. Can. J. Microbiol. 59:87-96.

Funnell-Harris, D. L., Sattler, S. E., O’Neill, P. M., Eskridge, K. M., and Pedersen, J. F. 2015. Effect of waxy (low amylose) on fungal infection of sorghum grain. Phytopathology 105:786-796.
Funnell-Harris, D. L., Scully, E. D., Sattler, S. E., French, R. C., O’Neill, P. M., and Pedersen, J. F. 2017. Differences in Fusarium species in brown midrib sorghum and in air populations in production fields. Phytopathology 107:1353-1363.

Geiser, D. M., del Mar Jimenez-Gasco, M., Kang, S., Makalowska, I., Veeraraghavan, N., Ward, T. J., Zhang, N., Kuldua, G. A., and O'Donnell, K. 2004. FUSARIUM-id v. 1.0: A DNA sequence database for identifying Fusarium. Eur. J. Plant Pathol. 110:473-479.

Gilbert, J., Brule-Babel, A., Guerrieri, A. T., Clear, R. M., Patrick, S., Slusarenko, K., and Wolfe, C. 2014. Ratio of 3-ADON and 15-ADON isolates of Fusarium graminearum recovered from wheat kernels in Manitoba from 2008 to 2012 Can. J. Plant Pathol. 36:54-63.

Gilbert, J., and Fernando, W. G. D. 2004. Epidemiology and biological control of Gibberella zeae/Fusarium graminearum. Can. J. Plant Pathol. 26:464-472.

Goswami, R. S., and Kistler, H. C. 2005. Pathogenicity and in plant mycotoxin accumulation among members of the Fusarium graminearum species complex on wheat and rice. Phytopathology 95:1397-1404.

Graybosch, R. A. 1998. Waxy wheats: Origins, properties and prospects. Trends Food Sci. Technol. 9:135-142.

Graybosch, R. A., Baenziger, P. S., Bowden, R. L., Dowell, F., Dykes, L., Jin, Y., Marshall, D. S., Ohm, J.-B., and Caffe, M. 2018. Release of 19 waxy winter wheat germplasm with observations on their grain stability. J. Plant Regist. 12:152-156.

Graybosch, R. A., Baenziger, P. S., Santra, D., Regassa, T., Jin, Y., Kolmer, J., Bai, G., St. Amand, P., Chen, R., and Seabourn, B. In press. Registration of 'Matterhorn' hard white waxy winter wheat. J. Plant Regist.

Graybosch, R. A., Baenziger, P. S., Santra, D. K., Regassa, T., Jin, Y., Kolmer, J., Wegulo, S., Bai, G., St. Amand, P., Chen, X., Seabourn, B., Dowell, F., Bowden, R., and Marshall, D. M. 2014. Registration of 'Mattern' waxy (amylose-free) winter wheat. J. Plant Regist. 8:43-48

Graybosch, R. A., Guo, G., and Shelton, D. R. 2000. Aberrant falling numbers of waxy wheats independent of $\alpha$-amylase activity. Cereal Chem. 77:1-3.

Graybosch, R. A., and Hansen, L. E. 2016. Functionality of chemically modified waxy, partial waxy and wild-type starches from common wheat. Starch/Stärke 68:496-504.

Graybosch, R. A., Souza, E., Berzonsky, W., Baenziger, S. P., and Chung, O 2003. Functional properties of waxy wheat flours: Genotypic and environmental effects. J. Cereal Sci. 38:69-76.

Guo, G., Jackson, D. S., Graybosch, R. A., and Parkhurst, A. M. 2003. Asian salted noodle quality: Impact of amylose content adjustments using waxy wheat flour. Cereal Chem. 80:437-445.

Hietaniemi, V., Ramo, S., Yli-Mattila, T., Jestol, M., Peltonen, S., Kartio, M., Siefilainen, E., Koivisto, T., and Parikka, P. 2016. Updated survey of Fusarium species and toxins in Finnish cereal grains. Food Addit. Contam. Part A 33:831-848.

Hubert, J., Nesvorna, M., and Kopecky, J. 2014. The effect of Tyrophagus putrescentiae on Fusarium poae transmission and fungal community in stored barley in a laboratory experiment. Insect Sci. 21:65-73.

Hung, P. V., Maeda, T., and Morita, N. 2006. Waxy and high-amylose wheat starches and flours-Characteristics, functionality and application. Trends Food Sci. Technol. 17:448-456.

Hung, P. V., Yasui, T., Maeda, T., and Morita, N. 2008. Physicochemical characteristics of starches of two sets of near-isogenic wheat lines with different amylose content. Starch/Stärke 60:34-40.

Jensen, B. D., Knorr, K., and Nicolaisen, M. 2016. In vitro competition between Fusarium graminearum and Epicoccum nigrum on media and wheat grains. Eur. J. Plant Pathol. 146:657-670.

Jiao, F., Kawakami, A., and Nakajima, T. 2008. Effects of different carbon sources on trichothecene production and Tri gene expression by Fusarium graminearum in liquid culture. FEMS Microbiol. Lett. 285:212-219.

Jin, F., Zhang, D., Bockus, W., Baenziger, S. P., Carver, B., and Bai, G. 2013. Fusarium head blight resistance in U.S. winter wheat cultivars and elite breeding lines. Crop Sci. 53:2006-2013.

Johnson, V. A., and Beemer, J. H. L. 1977. Wheat in the People's Republic of China: A Report of the American Wheat Studies Delegation. National Academy of Sciences, Washington, DC

Kang, H.-J., Hwang, I.-K., Kim, K.-S., and Choi, H.-C. 2006. Comparison of the physicochemical properties and ultrastructure of japonica and indica rice grains. J. Agric. Food Chem. 54:4833-4838.

Katika, M. R., Hendriksen, P. J. M., Shao, J., van Loveren, H., and Peijnenburg, A. 2012. Transcriptome analysis of the human T lymphocyte cell line Jurkat and human peripheral blood mononuclear cells exposed to deoxynivalenol (DON): New mechanistic insights. Toxicol. Appl. Pharmacol. 264:51-64.

Kenward, M. G., and Roger, J. H. 1997. Small sample inference for fixed effects from restricted maximum likelihood. Biometrics 53:983-997.

Kharbikar, L. L., Dickin, E. T., and Edwards, S. G. 2015. Impact of post-anthesis rainfall, fungicide and harvesting time on the concentration of deoxynivalenol and zearalenone in wheat. Food Addit. Contam. Part A 32:2075-2085.

Koch, H.-J., Pringas, C., and Maerlaender, B. 2006. Evaluation of environmental and management effects on Fusarium head blight infection and deoxynivalenol concentration in the grain of winter wheat. Eur. J. Agron. 24:357-366.

Kosiak, B., Torp, M., Skjerve, E., and Andersen, B. 2004. Alternaria and Fusarium in Norwegian grain of reduced quality-A matched pair sample study. Int. J. Food Microbiol. 93:51-62. 
Kowalski, R. J., Meldrum, A., Wang, S., Joyner (Melito), H., and Ganjyal, G. M. 2017. Waxy wheat flour as a freeze-thaw stable ingredient through rheological studies. Food Bioprocess Technol. 10:1281-1296.

Kubo, K., Kawada, N., Nakajima, T., Hirayae, K., and Fujita, M. 2014. Field evaluation of resistance to kernel infection and mycotoxin accumulation caused by Fusarium head blight in western Japanese wheat (Triticum aestivum L.) cultivars. Euphytica 200:81-93.

Lee, S. B., and Taylor, J. W. 1990. Isolation of DNA from fungal mycelia and single spores. Pages 282-287 in: PCR Protocols: A Guide to Methods and Applications. M. A. Innis, D. H. Gelfand, J. J. Sninsky, and T. J. White, eds. Harcourt Brace Jovanovich, San Diego, CA.

Leplat, J., Friberg, H., Abid, M., and Steinberg, C. 2013. Survival of Fusarium graminearum, the causal agent of Fusarium head blight: A review. Agron. Sustain. Dev. 33:97-111.

Leslie, J. F., and Summerell, B. A. 2006. The Fusarium Laboratory Manual. Blackwell, Ames, IA.

Lilleboe, D. 2015. FHB in 2015: A vexing year, overall. Article 2015FHB 20102026-2015. U.S. Wheat and Barley Scab Initiative.

Lin, B.-N., Hsu, Y.-C., Kuo, S.-C., Lin, Y.-R., Wu, Y.-P., and Kuo, C.-W. 2017. Novel $W x$ alleles induced by chemical mutagens in rice, Oryza sativa L. Plant Breed. 136:206-213.

Lincy, S. V., Chandrashekar, A., Narayan, M. S., Sharma, R., and Thakur, R. P. 2011. Natural occurrence of trichothecene-producing Fusaria isolated from India with particular reference to sorghum. World J. Microbiol. Biotechnol. 27:981-989.

Loesch, J. P. J., Foley, D. C., and Cox, D. F. 1976. Comparative resistance of opaque2 and normal inbred lines of maize to ear-rotting pathogens. Crop Sci. 16:841-842.

Lutz, M. P., Feichtinger, G., Defago, G., and Duffy, B. 2003. Mycotoxigenic Fusarium and deoxynivalenol production repress chitinase gene expression in the biocontrol agent Trichoderma atroviride P1. Appl. Environ. Microbiol. 69:3077-3084

Malbrán, I., Mourelos, C. A., Girotti, J. R., Balatti, P. A., and Lori, G. A. 2014. Toxigenic capacity and trichothecene production by Fusarium graminearum isolates from Argentina and their relationship with aggressiveness and fungal expansion in the wheat spike. Phytopathology 104:357-364.

Mangalika, W. H. A., Miura, H., Yamauchi, H., and Noda, T. 2003. Properties of starches from near-isogenic wheat lines with different Wx protein deficiencies. Cereal Chem. 80:662-666.

Maningat, C. C., and Seib, P. A. 2010. Understanding the physicochemical and functional properties of wheat starch in various foods. Cereal Chem. 87:305-314.

Manstretta, V., Gourdain, E., and Rossi, V. 2015. Deposition patterns of Fusarium graminearum ascospores and conidia within a wheat canopy. Eur. J. Plant Pathol. 143:873-880.

Marín, P., Moretti, A., Ritieni, A., Jurado, M., Vasquez, C., and Gonzalez-Jaen, M. T. 2012. Phylogenetic analyses and toxigenic profiles of Fusarium equiseti and Fusarium acuminatum isolated from cereals from Southern Europe. Food Microbiol. 31:229-237.

Markell, S. G., and Francl, L. J. 2003. Fusarium head blight inoculum: Species prevalence and Gibberella zeae spore type. Plant Dis. 87:814-820.

McMullen, M., Bergstrom, G., De Wolf, E., Dill-Macky, R., Hershman, D., Shaner, G., and Van Sanford, D. 2012. A unified effort to fight an enemy of wheat and barley: Fusarium head blight. Plant Dis. 96:1712-1728.

McMullen, M., Jones, R., and Gallenberg, D. 1997. Scab of wheat and barley: A reemerging disease of devastating impact. Plant Dis. 81:1340-1348.

Miura, H., Tanii, S., Nakamura, T., and Watanabe, N. 1994. Genetic control of amylose content in wheat endosperm starch and differential effects of three Wx genes. Theor. Appl. Genet. 89:276-280.

Morante, N., Ceballos, H., Sanchez, T., Rolland-Sabate, A., Calle, F., Hershey, C., and Gibert, O. 2016. Discovery of new spontaneous sources of amylose-free cassava starch and analysis of their structure and techno-functional properties. Food Hydrocoll. 56:383-395.

Morris, C. F., and King, G. E. 2007. Registration of 'Waxy-Pen' soft white spring wheat. J. Plant Regist. 1:23-24.

Muthomi, J. W., Ndung, J. K., Gathumbi, J. K., Mutitu, E. W., and Wagacha, J. M. 2008. The occurrence of Fusarium species and mycotoxins in Kenyan wheat. Crop Prot. 27:1215-1219.

Mylona, K., Sulyok, M., and Magan, N. 2012. Relationship between environmental factors, dry matter loss and mycotoxin levels in stored wheat and maize infected with Fusarium species. Food Addit. Contam. 29:1118-1128.

Nakamura, T., Shimbata, T., Vrinten, P., Saito, M., Yonemaru, J., Seto, Y., Yasuda, H., and Takahama, M. 2006. Sweet wheat. Genes Genet. Syst. 81:361-365.

Nakamura, T., Yamamori, M., Hirano, H., and Hidaka, S. 1993. Decrease of waxy (Wx) protein in two common wheat cultivars with low amylose content. Plant Breed. 111:99-105.

Nakamura, T., Yamamori, M., Hirano, H., Hidaka, S., and Nagamine, T. 1995. Production of waxy (amylose-free) wheats. Mol. Gen. Genet. 248:253-259.

Nash, S. M., and Snyder, W. C. 1962. Quantitative estimations by plate counts of propagules of the bean root rot Fusarium in field soils. Phytopathology 52: 567-572.

Nicolaisen, M., Justesen, A. F., Knorr, K., Wang, J., and Pinnschmidt, H. O. 2014. Fungal communities in wheat grain show significant co-existence patterns among species. Fungal Ecol. 11:145-153.
Obanor, F., and Chakraborty, S. 2014. Aetiology and toxigenicity of Fusarium graminearum and $F$. pseudograminearum causing crown rot and head blight in Australia under natural and artificial infection. Plant Pathol. 63:1218-1229.

Osborne, L. E., and Stein, J. M. 2007. Epidemiology of Fusarium head blight on small-grain cereals. Int. J. Food Microbiol. 119:103-108.

Panthi, A., Hallen-Adams, H., Wegulo, S. N., Hernandez Nopsa, J., and Baenziger, S. P. 2014. Chemotype and aggressiveness of isolates of Fusarium graminearum causing head blight of wheat in Nebraska. Can. J. Plant Pathol. 36:447-455.

Paul, P. A., Lipps, P. E., and Madden, L. V. 2005. Relationship between visual estimates of Fusarium head blight intensity and deoxynivalenol accumulation in harvested wheat grain: A meta-analysis. Phytopathology 95:1225-1236.

Paulsen, G. M., and Shroyer, J. P. 2008. The early history of wheat improvement in the Great Plains. Agron. J. 100 (Supplement 3):S-70-S-78.

Raiola, A., Tenore, G. C., Manyes, L., Meca, G., and Ritieni, A. 2015. Risk analysis of main mycotoxins occurring in food for children: An overview. Food Chem. Toxicol. 84:169-180.

Ramachandran, A., Hucl, P., and Briggs, C. 2016. Functional characteristics of bread wheat (Triticum aestivum L.) near-isogenic lines differing at the Waxy $(W x)$ locus. Cereal Chem. 93:77-85.

Richard, E., Heutte, N., Sage, L., Pottier, D., Bouchart, V., Lebailly, P., and Garon, D. 2007. Toxigenic fungi and mycotoxins in mature corn silage. Food Chem. Toxicol. 45:2420-2425.

SAS. 2013. SAS 9.4 Help and Documentation. SAS Institute, Cary, NC

Sattler, S. E., Singh, J., Haas, E. J., Guo, L., Sarath, G., and Pedersen, J. F. 2009 Two distinct waxy alleles impact the granule-bound starch synthase in sorghum. Mol. Breed. 24:349-359.

Savi, G. D., Piacentini, K. C., Tibola, C. S., Santos, K., Sousa Maria, G., and Scussel, V. M. 2016. Deoxynivalenol in the wheat milling process and wheat-based products and daily intake estimates for the Southern Brazilian population. Food Control 62:231-236.

Schaafsma, A. W., Tamburic-Ilincic, L., and Hooker, D. C. 2005. Effect of previous crop, tillage, field size, adjacent crop, and sampling direction on airborne propagules of Gibberella zeae/Fusarium graminearum, Fusarium head blight severity, and deoxynivalenol accumulation in winter wheat. Can. J. Plant Pathol. 27:217-224

Seib, P. A. 2000. Reduced-amylose wheat and Asian noodles. Cereal Foods World 45:504-512.

Shah, D. A., Molineros, J. E., Paul, P. A., Willyerd, K. T., Madden, L. V., and De Wolf, E. D. 2013. Predicting Fusarium head blight epidemics with weather-driven pre- and post-anthesis logistic regression models. Phytopathology 103:906-919.

Shevkani, K., Singh, N., Bajaj, R., and Kaur, A. 2017. Wheat starch production, structure, functionality and applications-A review. Int. J. Food Sci. Technol. 52:38-58.

Spanic, V., Lemmens, M., and Drezner, G. 2010. Morphological and molecular identification of Fusarium species associated with head blight on wheat in east Croatia. Eur. J. Plant Pathol. 128:511-516.

Stack, J. P., and Pedersen, J. F. 2003. Expression of susceptibility to Fusarium head blight and grain mold in $\mathrm{A}_{1}$ and $\mathrm{A}_{2}$ cytoplasms of Sorghum bicolor. Plant Dis. 87:172-176.

Svihus, B., Uhlen, A. K., and Harstad, O. M. 2005. Effect of starch granule structure, associated components and processing on nutritive value of cereal starch: A review. Anim. Feed Sci. Technol. 122:303-320.

Tittlemier, S. A., Roscoe, M., Trelka, R., Gaba, D., Chan, J. M., Patrick, S. K., Sulyok, M., Krska, R., McKendry, T., and Grafenhan, T. 2013. Fusarium damage in small cereal grains from western Canada. 2. Occurrence of Fusarium toxins and their source organisms in durum wheat harvested in 2010. J. Agric. Food Chem. 61:5438-5448.

Tkachuk, R., Dexter, J. E., Tipples, K. H., and Nowicki, T. W. 1991. Removal by specific gravity table of tombstone kernels and associated trichothecenes from wheat infected with Fusarium head blight. Cereal Chem. 68:428-431.

Tokai, T., Koshino, H., Takahashi-Ando, N., Sato, M., Fujimura, M., and Kimura, M. 2007. Fusarium Tri4 encodes a key multifunctional cytochrome P450 monooxygenase for four consecutive oxygenation steps in trichothecene biosynthesis. Biochem. Biophys. Res. Commun. 353:412-417.

Trigo-Stockli, D. M., Deyoe, W., Satumbaga, R. F., and Pedersen, J. R. 1996 Distribution of deoxynivalenol and zearalenone in milled fractions of wheat. Cereal Chem. 73:388-391.

Umpiérrez-Failache, M., Garmendia, G., Pereyra, S. A., Rodriguez-Haralambides, A., Ward, T. J., and Vero, S. 2013. Regional differences in species composition and toxigenic potential among Fusarium head blight isolates from Uruguay indicate a risk of nivalenol contamination in new wheat production areas. Int. J. Food Microbiol. 166:135-140.

VanEtten, H. D., and Bateman, D. F. 1971. Studies on the mode of action of the phytoalexin phaseollin. Phytopathology 61:1363-1372.

Varga, E., Wiesenberger, G., Hametner, C., Ward, T. J., Dong, Y., Stuckler, R., Shuhmacher, R., Krska, R., Kistler, H. C., Berthiller, F., and Adam, G. 2015. New tricks of an old enemy: Isolates of Fusarium graminearum produce a type A trichothecene mycotoxin. Environ. Microbiol. 17:2588-2600.

Vasavada, A. B., and Hsieh, D. P. H. 1987. Production of 3-acetyldeoxynivalenol by Fusarium graminearum R 2118 in submerged cultures. Appl. Microbiol. Biotechnol. 26:517-521. 
Vrinten, P., and Nakamura, T. 2000. Wheat granule-bound starch synthase I and II are encoded by separate genes that are expressed in different tissues. Plant Physiol. 122:255-264.

Vujanovic, V., Goh, Y. K., and Daida, P. 2012. Heat- and cold-shock responses in Fusarium graminearum 3 acetyl-and 15 acetyl-deoxynivalenol chemotypes. J. Microbiol. 50:97-102.

Wagacha, J. M., Steiner, U., Dehne, H.-W., Zuehlke, S., Spiteller, M., Muthomi, J., and Oerke, E.-C. 2010. Diversity in mycotoxins and fungal species infecting wheat in Nakuru District, Kenya. J. Phytopathol. 158:527-535.

Wegulo, S. N., Bockus, W. W., Hernandez Nopsa, J., De Wolf, E. D., Eskridge, K. M., Peiris, K. H. S., and Dowell, F. E. 2011. Effects of integrating cultivar resistance and fungicide application on Fusarium head blight and deoxynivalenol in winter wheat. Plant Dis. 95:554-560.
Windels, C. E., Burnes, P. M., and Kommedahl, T. 1988. Five-year preservation of Fusarium species on silica gel and soil. Phytopathology 78:107-109.

Yasui, T., and Ashida, K. 2011. Waxy endosperm accompanies increased fat and saccharide contents in bread wheat (Triticum aestivum L.) grain. J. Cereal Sci. 53:104-111.

Zadoks, J. C., Chang, T. T., and Konzak, C. F. 1974. A decimal code for the growth stages of cereals. Weed Res. 14:415-421.

Zeller, K. A., Bowden, R. L., and Leslie, J. F. 2003. Diversity of epidemic populations of Gibberella zeae from small quadrats in Kansas and North Dakota. Phytopathology 93:874-880.

Zhang, H., and Wang, B. 2015. Fates of deoxynivalenol and deoxynivalenol3 -glucoside during bread and noodle processing. Food Control 50: 754-757. 